FEDERAL RESERVE BANK OF SAN FRANCISCO

WORKING PAPER SERIES

\title{
The Extent and Cyclicality of Career Changes: Evidence for the U.K.
}

\author{
Carlos Carrillo-Tudela \\ University of Essex, CESifo and IZA \\ Bart Hobijn \\ Federal Reserve Bank of San Francisco \\ Powen She \\ University of Essex \\ Ludo Visschers \\ The University of Edinburgh, Universidad Carlos III \\ and CESifo
}

August 2014

Working Paper 2014-21

http://www.frbsf.org/economic-research/publications/working-papers/wp2014-21.pdf

The views in this paper are solely the responsibility of the authors and should not be interpreted as reflecting the views of the Federal Reserve Bank of San Francisco or the Board of Governors of the Federal Reserve System. 


\title{
The Extent and Cyclicality of Career Changes: Evidence for the U.K.*
}

\author{
Carlos Carrillo-Tudela ${ }^{\dagger}$ \\ University of Essex, \\ CESifo and IZA
}

\author{
Bart Hobijn ${ }^{\ddagger}$
}

Federal Reserve Bank

of San Francisco

Ludo Visschers ${ }^{\S}$

The University of Edinburgh,

Universidad Carlos III

and CESifo

August 27, 2014

\author{
Powen She \\ University of Essex
}

\begin{abstract}
Using quarterly data for the U.K. from 1993 through 2012, we document that in economic downturns a smaller fraction of unemployed workers change their career when starting a new job. Moreover, the proportion of total hires that involves a career change for the worker also drops in recessions. Together with a simultaneous drop in overall turnover, this implies that the number of career changes declines during recessions. These results indicate that recessions are times of subdued reallocation rather than of accelerated and involuntary structural transformation. We back this interpretation up with evidence on who changes careers, which industries and occupations they come from and go to, and at which wage gains.
\end{abstract}

Keywords: Labour market turnover, occupational and industry mobility, wage growth.

JEL: J63, J64, G10.

\footnotetext{
*We would like to thank the audience of the "Unemployment, Wage Inequality and Labour Market Policy" workshop in Konstanz for their comments and suggestions, and in particular to Ija Trapeznikova for her discussion of an earlier version of this paper. We would also like to thank Pedro Gomes for his generous help with the U.K. LFS. The usual disclaimer applies.

${ }^{\dagger}$ Corresponding author: Department of Economics, University of Essex, Wivenhoe Park, Colchester, CO4 3SQ, UK; cocarr@essex.ac.uk. Carlos Carrillo-Tudela acknowledges financial support from the UK Economic and Social Research Council (ESRC), award reference ES/I037628/1.

${ }^{\ddagger}$ The views in this paper are solely the responsibility of the authors and should not be interpreted as reflecting the views of the Federal Reserve Bank of San Francisco or the Federal Reserve System.

${ }^{\S}$ Ludo Visschers acknowledges financial support from the Juan de la Cierva Fellowship, Project Grant ECO201020614 from the Spanish Ministry of Science and Innovation, and the Bank of Spain's Programa de Investigación de Excelencia.
} 


\section{Introduction}

One of the most important functions of the labour market is to pair the right set of workers with the right set of jobs. This assignment process, however, is slowed down by frictions that impede the reallocation of labour resources. For example, moving costs, re-training, learning about one's ability, information frictions about the location of workers or jobs, among others, can be important barriers for efficient resource reallocation. The result of these frictions is that we observe large concurrent flows of workers changing jobs directly from employer to employer as well as through spells of unemployment. This excess churning is a common feature of all labour markets in OECD countries. $^{1}$

One view is that recessions "cleanse" the labour market by speeding up the reallocation of workers that was prevented from occurring by frictions during the preceding expansion. ${ }^{2}$ This view is appealing because it provides a possible explanation for why unemployment is persistently high in recessions. It simply takes workers time to switch from jobs in industries and occupations for which demand is in secular decline to jobs in growing segments of the labour market.

In this paper we show that, though this might be appealing in theory, there is little support for it in the data. We do so by documenting the prevalence of career changes, as in workers taking jobs in a different industry or occupation than they previously worked in, over the business cycle in the British labour market.

The U.K. has one of the most flexible labour markets in Europe and exhibits one of the highest levels of worker turnover in the OECD (see Jolivet et. al, 2006). Figure 1 shows that the period, from 1993 through 2013, that we study can be split up into four distinct episodes. The first is a period of economic expansion until 2001, during which the unemployment rate declined by about 4 percentage points. ${ }^{3}$ The second is a period of slow growth following 2001, when the U.K. economy skirted a recession and the unemployment rate blipped up. The third episode is the economic expansion from 2002 until the start of the Great Recession in 2008. The Great Recession and its aftermath make up the final episode. Figure 1 shows that the unemployment rate increased by 3 percentage points during that period.

It is the number and rate of industry and occupation changes, as well as the associated wage changes, in this final episode that we compare with the earlier part of our sample. For this, we use individual-level data from the U.K. Quarterly Labor Force Survey.

In the first part of our analysis, we focus on $(i)$ the extent of career changes in the labour market and (ii) how they fluctuate over the business cycle. In the second part we shine a light on what drives these career changes by documenting $(i)$ who change careers, (ii) which industries and occupations they come from and go to, and (iii) whether they do so at higher or lower wage gains than those of other workers. Five main findings emerge from our analysis.

The extent of career changes is high. A worker who changes employers has around a $50 \%$ chance of switching to another occupation or industry. The rates of career changes are remarkably similar for those that change employers with or without an intervening spell of non-employment. These career changes in large part reflect excess churning in the labour market. The actual net

\footnotetext{
${ }^{1}$ See Davis, 1987, and Jolivet et. al, 2006, among others

${ }^{2}$ See, for example, Lilien, 1982, Mortensen and Pissarides, 1994, Caballero and Hammour, 1994, Groshen and Potter, 2003, and Jaimovich and Siu, 2014.

${ }^{3}$ Recession dates are taken from Economic Cycle Research Institute (ECRI,2014).
} 
mobility across industries and occupations due to career switches only amounts to $10 \%$ and $15 \%$ of the overall flows between occupations and industries respectively.

Our results build on those in Longhi and Taylor (2011), who use the same data source as we do and find that the extent of occupational mobility in the U.K. is high. The high rates of occupational and industry mobility that we find are not specific to the U.K. Several studies, based on various different data sources, have shown this is also the case in the U.S. ${ }^{4}$

Career changes decrease in recessions: The total number of workers that change careers and the probability of a career change are procyclical. Moreover, the probability of a career change is also procyclical when conditioning on workers changing employers directly, experiencing a spell of non-participation, or a spell of unemployment. This finding elaborates on earlier similar results for the U.S. ${ }^{5}$ Just like in the U.S., in the U.K. excess churning is the main driver of the cyclicality of overall mobility across occupations or industries. This is because job-to-job transitions, that account for the bulk of this churning, are procyclical. ${ }^{6}$

Characteristics of career changers: Career changes are more likely for $(i)$ those workers actively searching for a job, (ii) those that made voluntary transitions, and (iii) those workers that work part-time or as temps. In terms of demographics, young workers and women are more prone to change careers than their older and male counterparts. Even after accounting for these characteristics, the propensity to change careers for workers that start a new job remains procyclical. Thus, our results are not due to changes in the composition of who gets hired over the business cycle.

Career Paths: Across occupations, career changes that involve an upgrade in the skill level are more likely through a direct employer-to-employer transitions. On the contrary, career changes that involve a step down in skill level are more likely after spells of non-employment. This reflects that voluntary career moves tend to be upward while involuntary ones often push workers down a rung on the career ladder.

Career changes are associated with wage gains: The majority of career changes come with wage increases and these wage increases tend to be bigger than for those workers that change jobs but remain in the same career. The wage gains for those who got hired out of unemployment and changed occupations fell during the recession and became smaller than the wage gains of those who did not change occupations.

Taken together, these results support the view that the Great Recession and its aftermath was a period in which there was a shortfall in demand and economic activity that affected workers across a large set of industries and occupations and prevented them from pursuing alternate careers at substantial wage gains. In this sense, our results are consistent with Barlevy (2002). He argues that since employment-to-employment transitions are large and procyclical, economic expansions, rather than recessions, are times in which labour resources tend to reallocate to better uses.

\footnotetext{
${ }^{4}$ See Kambourov and Manovskii (2009), using the PSID, Xiong (2008), using the SIPP, and Carrillo-Tudela, Hobijn and Visschers (2014) and Carrillo-Tudela and Visschers (2014).

${ }^{5}$ For example, Murphy and Topel (1987), Carrillo-Tudela, Hobijn and Visschers (2014), and Carrillo-Tudela and Visschers (2014) have all documented the procyclicality of occupational and/or industry mobility in the U.S. labour market.

${ }^{6}$ Moscarini and Thomsson (2007), Moscarini and Vella (2008) and Kambourov and Manovskii (2008), find that occupational mobility of employed workers in the U.S. over time is also driven by the prevalence of job-to-job transitions.
} 


\section{Data and definitions}

\subsection{Structure of the U.K. Quarterly Labour Force Survey}

The data we use are from the U.K. Quarterly Labour Force Survey (LFS) and cover the period 1993Q1-2012Q3. The LFS has a rotating panel structure, depicted in Figure 2, in which individuals that live on the sampled address are followed for a maximum of 5 quarters, also referred to as waves. Each quarter, one-fifth of the sample of addresses is replaced by an incoming rotation group, or cohort. From this sample, we consider all male workers between 16 and 65 years of age and all female workers between 16 and 60 years of age with an ongoing career. ${ }^{7}$

In each wave, the respondents provide information about, among other things, their labour market status as well as their occupation and the industry they work in if they are employed and if non-employed they provide the occupation and industry of their previous job. Because we are interested in those workers who switch jobs and potentially change careers, we need observations on workers for two consecutive quarters. Thus, we use the two-quarter (2Q) longitudinal sample of the LFS. Two quarters of this sample are depicted in Figure 2 as long-dashed rectangles, labeled "2Q". As can be seen from the figure, because of the rotating panel structure and sample attrition, the $2 \mathrm{Q}$ sample is smaller than the quarterly cross-section. It consists of about 60,000 individuals each quarter.

We record a career change when a worker changed employer and reported an occupation or industry in the new job that is different from the occupation or industry reported in the last job held. What is flagged as a career change in our data depends on the level of aggregation of the occupation and industry classifications used. To make sure we capture substantial career changes we only flag a new job as a career change if it involves working in either a different major occupation or major industry as the worker did before. ${ }^{8}$

The Standard Occupation Classification (SOC) categories that we use are redefined twice during our sample period. The first time is in 2001 and the second time at the end of 2010 . We correct for the first revision of the SOC categories by splicing our results together between the 1993-2001 and 2002-2010 period, using the method described in the Appendix. Because our sample is very short after 2010, such splicing is not possible for the latter period. Consequently, we end the sample used to calculate results for occupations in 2010Q4. The U.K. LFS did not ask respondents about their industry of employment before 1994, such that our results for industries cover 1994-2012. In sum, our results for occupations and industries cover slightly different time periods.

For part of our analysis, we analyze the change in wages that career changes result in. Individuals in the LFS only report their wages in the first and fifth waves. These are depicted by the circles labeled "W" in Figure 2. Because they report their wages one year apart, we can calculated annual wage growth for these workers. However, to do so requires us to follow these workers for the full five quarters that they are in the LFS. This sample is known as the five-quarter longitudinal sample and is depicted by the short-dashed rectangle labeled " $5 \mathrm{Q}$ " in the figure. This sample contains, on

\footnotetext{
${ }^{7}$ That is those workers that provided information on occupation or industry. Note that around $10 \%$ of those workers that start jobs with a new employer do not report information on occupation or industry. These are mainly young workers for whom this is, presumably, their first job.

${ }^{8}$ Because of the address being the sampling unit of the LFS, we do not capture career changes in which people move to a different address. In that case they drop out of the sample. Moreover, given the quarterly nature of the data in the LFS, we are unable to record a worker's transitions within any given quarter and hence our estimates will miss these potential job changes. That is, our results are affected by time-aggregation bias.
} 
average, about 11,000 individuals.

\subsection{Level and probability of career changes}

Since mobility across employers and careers can occur with or without intervening spells of nonemployment, we analyse mobility across jobs by considering employment to employment $(E E)$ transitions, unemployment to employment $(U E)$ transitions, and inactivity (non-participant in the labour force) to employment ( $I E)$ transitions. We denote the labour market status of a worker in the quarter before he or she starts a new job as $S \in\{E, U, I\}$. Conditioning on labour market status history is informative, because it is a signal of the reason why a worker might decide to pursue a different career.

Throughout, we split the three types of flows, EE, UE, and $I E$, up by career movers, denoted by $m$, and career stayers, denoted by $s$. Career movers are those workers that work for a new employer in either a different occupation or industry as they worked in before. Career stayers are workers that start a new job in the same occupation and industry they worked in previously. In terms of this notation, $E E_{t+1}$ is the total number of workers that move from one employer in quarter $t$ to another in quarter $t+1$ and $E E m_{t+1}$ is the number of those workers who switch careers. $^{9}$

These definitions allow us to consider the quarterly proportion of all new hires that experienced a change in occupation or industry in period $t+1$, given that in period $t$ their labour market state was $S \in\{E, U, I\}$. Namely,

$$
H S m_{t}=\frac{S E m_{t+1}}{S E_{t+1}} .
$$

Aggregating over all three labour market statuses, $S \in\{E, U, I\}$, we obtain that the proportion of total hires that are career movers is given by

$$
H m_{t}=\frac{U E m_{t+1}+I E m_{t+1}+E E m_{t+1}}{U E_{t+1}+I E_{t+1}+E E_{t+1}} .
$$

We use these measures as estimates of the probability of a career change conditional on starting a new job, the previous labour market status, and being in an ongoing career. The levels of the flows and these estimated career change probabilities are the main statistics we focus on in our analysis.

\subsection{Net mobility}

Theories that emphasize the cleansing effect of recessions on the labour market emphasize how downturns accelerate the shift in labour market resources from segments that are in structural decline to those that are on a positive long-run trend. These are theories that focus on the net mobility of workers across professions and sectors.

Net mobility is given by

$$
N M_{t}=\sum_{i=1}^{K}\left|I_{i, t}-O_{i, t}\right|,
$$

where $I_{i, t}$ is the number of career movers that start a new career in sector (or occupation), $i$.

\footnotetext{
${ }^{9}$ We similarly define $E E s_{t}, U E_{t}, U E m_{t}, U E s_{t}, I E E_{t}, I E m_{t}$, and $I E s_{t}$.
} 
Similarly, $O_{i, t}$ is the number of workers that leave sector (or occupation) $i$ to pursue a different career.

To put this net mobility in the context of the magnitude of overall flows in the labour market, we follow Davis and Haltiwanger (1992) and analyze excess reallocation. That is, we quantify by how much the total gross reallocation measured by the flows introduced in the previous subsection exceeds the minimum flows needed to achieve the net shift in the allocation of workers across occupations and industries observed.

In particular, we use the following proxy of the fraction of gross reallocation needed to achieve the net reallocation in the data. This net mobility rate, $n m_{t}$, is defined as

$$
n m_{t}=\sum_{i=1}^{K}\left[\frac{\left|I_{i, t}-O_{i, t}\right|}{I_{i, t}+O_{i, t}}\right] \omega_{i, t},
$$

We weigh the sector (or occupation) specific flows by $\omega_{i, t}$, which is the employment share of the respective industry or occupation at time $t$. Our data allow us to compute separate quarterly series, $N M_{t}$ and $n m_{t}$, for occupations and industries.

\section{The Extent and Cyclicality of Career Changes}

In this section we investigate both the level as well as the cyclical fluctuations of the incidence of career changes in the U.K. labour market. In the first subsection we focus on the level and report long-run averages over our whole sample period. In the second subsection we shift our focus to how the prevalence of career changes moves over the business cycle.

\subsection{Long-run averages}

The U.K. labour market displays a surprising degree of churning. Over our sample period, the sum of career movers and stayers is on average 1.3 million. This amounts to $4.5 \%$ of the U.K.'s working age population. Of those who get hired and have a previous career, $43 \%$ come directly from a previous job, $29 \%$ are hired out of unemployment, and $29 \%$ were out of the labour force. These numbers are in line with Gomes (2012).

What is even more striking is the high share of these hires that involve a career change. Table 1 shows the average fraction of these hires that we classify as a career change. As can be seen from the top row of the table, $49 \%$ of those workers with a previous career who start a new job do so in a different (major) occupation from which they worked in before. This fraction is even higher for industries, for which the majority, 53\%, of such hires involve a switch in major industry.

The similarities in the extent of career changes across occupations or industries arises mostly because the majority of career movers change occupations and industries at the same time. For example, on average $75 \%$ of workers who changed occupations also changed industries and $70 \%$ of workers who changed industries also changed occupations.

Though high, these numbers are in line with evidence for the United States. For example, Carrillo-Tudela, Hobijn and Visschers (2014), using data from the Current Population Survey, and Carrillo-Tudela and Visschers (2014), who rely on the Survey of Income and Program Participation, both find that about half of the hires in the United States involve a career change as well. 
One caveat is important to note. Reporting errors, more so for occupations than for industries, are common in surveys like the U.K. LFS. If estimates from other datasets are applied to our results for the U.K. LFS, then, maybe even as much as a quarter, of the career moves that we measure could be due to workers misreporting their occupation and/or industry in the survey. ${ }^{10}$ However, even if this is true, this would still mean that about a third of all hires of persons with previous work experience involves them changing either the industry or profession that they work in. Even after such a drastic downward adjustment, this would imply that more than one percent of the U.K. working age population switches careers every quarter.

Rows 2 and up of Table 1 list the probability of a career change conditional on the labour market status of the worker in the quarter before she or he starts a new job. As can be seen from the table, the average probability of a career change is around $50 \%$ for each of these types of hires.

Two groups of workers stand out as having a higher probability of switching careers than others. The first consists of workers who make an $E E$ transition and who actively searched for the new position in the old job. These are mostly workers who actively pursue a voluntary change in their career path. ${ }^{11}$

The second group of workers with a higher probability of moving to a different career are those who were unemployed for two quarters or more in the quarter before they started their new jobs. These tend to reflect involuntary career decisions that occur in long spells of unemployment. Such career changes are often emphasized as driving up the natural rate of unemployment in the shortrun in the wake of a recession due to mismatch in the labour market. ${ }^{12}$ Recent studies show that mismatch can only account for a small part of overall fluctuations in the unemployment rate.

Most studies of mismatch in the labour market compare the composition of job openings by industry and occupation with the composition of the pool of unemployed workers. This assumes that it is the pool of unemployed workers that are required to make all the adjustments to make the skill composition of the labour supply adjust to the composition of skills demanded. It turns out that more than half of the workers that get hired out of unemployment end up making such an adjustment. Moreover, our results suggest that the large number of job-to-job career switchers helps to accelerate this adjustment process.

By providing a measure of the gap between the skill requirements needed to fill the stock of job openings and the skill composition of the pool of unemployed, measures of mismatch are a proxy for the net amount of reallocation needed in the labour market to equilibrate the supply of and demand for skills. However, gross mobility between careers far exceeds net mobility. The average net mobility rates, $n m_{t}$, over our sample period are $10 \%$ for occupations and $13 \%$ across industries. ${ }^{13}$ This echoes the findings for the U.S. of Jovanovic and Moffit (1990), Kambourov and Manovskii (2008) and Auray et. al (2014), who show that net mobility accounts for only a small proportion of gross mobility across industries and occupations.

\footnotetext{
${ }^{10}$ Mellow and Sider (1993) estimate a misreporting rate of about $20 \%$ for major occupations and $8 \%$ for major industry sector in the Current Population Survey for the U.S. Lynn and Sala (2006) find similar misreporting rates for the BHPS in the U.K.

${ }^{11}$ In the Appendix we describe how we group workers into the different categories such as voluntary or involuntary searchers as used in Table 1 and in subsection 4.1 below.

${ }^{12}$ See, for example, Smith (2012) and Patterson, Şahin, Topa, and Violante (2013) for a quantitative analysis of this type of mismatch in the U.K.

${ }^{13}$ The small contribution of net mobility is also present when considering transitions only through unemployment or only through employment. For the former case, the average net mobility rates are $17 \%$ for occupations and $20 \%$ for industries; while for the latter the rates are $12 \%$ for occupations and $15 \%$ for industries.
} 


\subsection{Cyclical fluctuations}

Whether recession are times of accelerated or of relatively slow reallocation in the labour market can, of course, not be gleaned from the long-run averages we reported so far. To answer this question we present evidence on the fluctuations in the extent and probabilities of career changes over our sample period in this subsection.

The evidence on the extent of career changes is depicted in Figure $3 .{ }^{14}$ It plots the six types of hires of workers with ongoing careers. The bottom three shaded areas are the career movers coming from unemployment, $U E m$, employment, $E E m$, and inactivity, $I E m$, respectively. The top three shaded areas plot the same flows but then for career stayers instead. The solid line in the middle is the number of career movers in the quarter, while the dashed line on top is the sum of career movers and stayers.

The first thing to take away from this figure is that overall turnover for workers with previous work experience is procyclical. This can be seen from the fact that the dashed line in the figure follows almost exactly the reverse pattern as the unemployment rate in Figure 1. The procyclicality of turnover in our data is mainly driven by people who move from job to job, i.e. by $E E m$ and $E E s$. As can be seen from Figure 3, the bulk of the hires of workers with an ongoing career are job-to-job hires. This is consistent with the turnover estimates for the U.K. in Hobijn and Sahin (2013) and for the United States. ${ }^{15}$

The solid line in Figure 3 reveals that, just like overall turnover, the number of career changes is procyclical. Job-to-job transitions, EEm, also make up the majority of career changes. The main driving force behind the incidence of career changes over the business cycle is that the number of workers that change jobs to pursue a different career declines substantially when the unemployment rate spikes.

This force is partly offset by the fact that the number of workers that change careers after a spell of unemployment increases during and in the wake of recessions. However, in the aftermath of the Great Recession this uptick in career changes after unemployment, $U E m$, was rather small. It pales in comparison to the decline in EEm flows during the same period and thus contributed very little to the fluctuations in reallocation in the labour market over the last business cycle.

Moreover, if one compares the number of $U E m$ and $U E s$ transitions in Figure 3, one can see that the number of workers that find a job after being unemployed and remain in the same career, increases more during recessions than the number of unemployed that end up taking a job in a different industry or occupation. This suggests that the probability of a career change for those workers hired out of unemployment actually declines rather than increases during the recession.

This is shown to be the case in Figure 4. It plots the time series of the unconditional probability of a career change for hires with previous work experience, $\mathrm{Hm}$, as well as this probability conditional on what labour market state they were hired from, i.e. $H S m$ for $S \in\{U, E, I\}$. The bold line in the figure shows that $\mathrm{Hm}$ declined during the recession for both occupation and industry changes. This decline is starker for changes across industries, shown in panel (b), than for changes across occupations, in panel (a).

\footnotetext{
${ }^{14}$ Throughout we show time series that are 5-quarter centered moving averages. Though this allows for symmetric centering, it could induce residual seasonality in our time series. However, tests for such seasonality do not reject the null hypothesis of its absence.

${ }^{15}$ See Lazear and Spletzer (2012) for evidence for the United States, for example.
} 
The short-dashed line is the probability that a hire out of unemployment changes careers. This probability also declined substantially during the Great Recession. One possible explanation for this is the increased incidence of workers being recalled to their previous job during downturns. For example, Fujita and Moscarini (2012) find that, in the U.S., those workers that become unemployed after being permanently separated from their previous jobs are much more likely to make an occupational change than those that were on layoff and recalled within 3 months. However, in the UK such recall practice is minimal and, hence, is thus not likely to affect the results presented here. What is more pertinent is that, on the supply side, workers who get laid off in recessions will first look for a job that is similar to the one they lost and slowly broaden their search. ${ }^{16}$ However, as Carrillo-Tudela and Visschers (2014) argue, workers take into account that they may be less likely to start a particularly successful career path during a recession, which reduces their incentives to change careers at any duration. On the labour demand side, because of the increased size of the pool of unemployed workers, employers are more likely to find candidates that more closely match the career profile they are looking for. Some studies, like Ravenna and Walsh (2012) and Sedláček (2014), suggest that employers also get more selective in their hiring practices during downturns.

Such an increase in the pickiness of employers about who they hire in downturns also affects the opportunities of those who are employed and are looking to change jobs and pursue a different career. These effects result in a decline in the fraction of job-to-job transitions that result in a switch in industry or occupation during recessions, as can be seen from the long-dashed line in Figure 4.

So far, we have focused on comparing the Great Recession with the previous episodes in the data. The procyclicality of the level and probability of career changes that we documented is robust to other ways of business cycle accounting. For example, it also shows up if one uses the Hodrick-Prescott (1997) filter to distinguish between trend and cycle in the unemployment rate and the time series plotted in Figures 3 and 4.

The bottom line of the above results is that recessions are not times of accelerated labour market reallocation that are prevented from happening during expansions due to frictions. Instead, workers tend to stay put in their respective occupations and industries when labour market opportunities for them dry up during downturns. Thus, the evidence on career changes in the U.K. points to recessions having a "sullying" rather than a "cleansing" effect on labour markets.

Another way to gauge the relative importance of these effects is to look at the fluctuations in net mobility, $N M$, over the business cycle. Net mobility for both occupations and industries are plotted in Figure 5.

If recessions had a major "cleansing" effect that resulted in a substantial shift in workers from occupations and industries in secular decline to those for which demand is booming, then net mobility would increase during the recession as well during the subsequent recovery. This is because during the recovery workers would gradually find jobs in careers different from those that they were in before. It is exactly this slow adjustment during the recovery that is often pointed to as a source of the jobless recoveries from the last three recessions in the U.S. (Groshen and Potter, 2003, and Jaimovich and Siu, 2014)

However, as Figure 5 shows, there is none such persistent spike in net mobility. Net mobility

\footnotetext{
${ }^{16}$ Indeed, the number of unemployed workers who found a job after an unemployment spell of less than 6 months and changed careers actually decreased during the Great Recession.
} 
briefly spiked at the onset of the Great Recession. This spike coincides with the wave of layoffs described by Elsby and Smith (2010). By the end of the recession net mobility rate had declined however. It did run up once more in 2011 when austerity measures were introduced that had a very differential effect across different sectors of the U.K. economy.

This evidence on net mobility, together with that on the level and probability of career changes presented above, confirms Barlevy's (2002) interpretation of the role of business cycle for labour market dynamics. He argues that, because labour turnover is higher during expansions than during downturns, the reallocation of labour market resources is procyclical rather than countercyclical.

\section{Career Changes: Why, Who, Where, and at What Wage Gains?}

In the previous section we used broad aggregate statistics on career changes to come to the conclusion that recessions predominantly have a 'sullying' rather than a 'cleansing' effect on the labour market. In this section we dive into the details underlying these aggregates and use additional information from the U.K. LFS to analyse the reasons for the career changes, who changes careers, what they do before and after the career change, and how the change affects their wages. This turns out to yield a wealth of corroborating evidence in support of the conclusion we drew based on the evidence presented in the previous section.

\subsection{Reasons for career change}

Unfortunately, the U.K. LFS survey does not directly ask respondents who take jobs in a different occupation or industry about the specific reason for their career change. However, some of the questions asked allow us to indirectly infer some of the potential reasons. In particular, we revisit the questions we first focused on in Table 1. That is, for those who move from job to job we consider whether this move was voluntary and whether or not they had been actively searching for a job before they switched. For those who were unemployed in the quarter before they started their new job, we consider the duration of their unemployment spell in that quarter.

Because $E E$ flows account for the bulk of the turnover in Figure 3, we focus on the evidence for job-to-job switchers first. Figure 6 divides up the $E E$ flows into movers and stayers and classifies them by whether or not they made a voluntary job-to-job switch, panels (a) and (c), and by whether they were actively searching on the job before they made the switch, panels (b) and (d).

The first thing that stands out from the figure is that the bulk of job-to-job transitions are voluntary. Moreover, the vast majority of these transitions is not the result of the worker actively searching for another job but rather of the worker getting a job offer without searching. These two facts imply that a lot of job changes are voluntary quits that are the result of employers searching out workers rather than the other way around.

It is the procyclicality of this type of hires that makes labour turnover move with the business cycle. This is also the type of hire that accounts for the procyclicality of EEm flows. This can be seen from the fluctuations in the numbers of voluntary movers, in panels (a) and (c), and of movers that did not actively search for a job, in panels (b) and (d). Thus, Figure 3 and 6 jointly point to voluntary job-to-job career changes due to workers being recruited for rather than finding a new job as the main driving force behind the procyclicality of career changes. 
This type of voluntary job and career switches stand in stark contrast to those that are the result of workers being displaced and involuntarily deciding to change careers after a spell of unemployment. Figure 7 splits up the probability of a career change for hires out of unemployment, $H U m$ plotted as the short-dashed line in Figure 4, by whether the worker was unemployed for less or more than 2-quarters before finding a new job. These two series are denoted by $\leq 2 Q$ and $>2 Q$ respectively.

Comparing the $\leq 2 Q$ and $>2 Q$ probabilities in the figure for the entire period, it is clear that those whose are unemployed for longer change careers more frequently. This is consistent with the finding of Faberman and Kudlyak (2012), who, using data from an on-line job-search website, find that workers apply more to vacancies outside their usual occupational field as their spell duration increases.

What is surprising is that the decline in $H U m$ in Figure 4 is not only because those who find a job after a short unemployment spell in the recession are more likely to find a job similar to the one they had before. Even the probability of a career change for those with unemployment spells longer than two quarters declined during the Great Recession. ${ }^{17}$

This contradicts the common perception, as expressed in Jaimovich and Siu (2014), that recessions are times of accelerated involuntary structural transformation. During such times a large number of workers supposedly gets displaced from jobs that will never come back and thus are forced to look for and take jobs in sectors and occupations different from those they worked in before.

One possible explanation for why the incidence of career changes among hires out of unemployment does not spike in the recession is that workers that get displaced from jobs that are in secular decline might decide to drop out of the labour force rather than to switch careers. This is especially a concern in the United States, where the labour force participation rate dropped by more than 3 percentage points in the five years after the start of the Great Recession. ${ }^{18}$ Such flows to inactivity, however, are not likely to be important in the U.K. where the labour force participation rate actually increased between 2007 and 2012.

\subsection{Who changes careers?}

Of course, the discussion in the previous subsection focuses on the Great Recession versus the rest of the sample. In addition, the evidence presented does not condition on other factors that might be correlated with the variables used to proxy for different reasons for a career change. Here we show that the procyclicality of the probability of career changes, shown in Figures 4 and 7 , is statistically significant even if one considers the whole sample and also corrects for factors that affect the probability of a career switch.

We do so by presenting Probit estimates derived from a model where the dependent variable is whether or not the hire of a worker with previous work experience results in a career change.

\footnotetext{
${ }^{17}$ At the beginning of the recession, looking at occupations, there is a temporary increase in the probability of an career change among those workers who, at that point, found a job after being unemployed for more than 2 quarters. Note that at this early moment in the recession, only few workers are covered by this statistic, and (or because) a large part of them have entered unemployed before the start of the recession. Instead, for the typical long-term unemployed of the Great Recession, who will only find a job after the second quarter of 2008, the probability of a career change is decreased substantially relative to its average value.

${ }^{18}$ See Daly et al. (2012), for example, for discussion of the decline of the U.S. labour force participation rate.
} 
The explanatory variables include a set of worker characteristics, properties of the job the worker is hired in, and variables that proxy for the potential reasons for why the worker changed careers or not. Because the availability of some of the variables related to the reasons for the career change depends on the labour market status of the worker before he or she accepted the new job, we present the Probit estimates not only for all hires but also condition them on what labour market status the worker had in the quarter before starting the new job. The estimation results are presented in Table $2 .{ }^{19}$

In terms of the effects of human capital on the probability of a career change, we find that age decreases the probability of a career change, suggesting the importance of on-the-job human capital accumulation. Educational attainment, however, affects occupations and industries differently. Across occupations, high and medium skilled workers have a higher probability of a career change than low skilled workers (our reference category). Across industries, we find that low skilled workers have a higher probability of a career change than medium and high skilled workers. These results seem to arise from differences in the impact of skill levels by employment status. Across occupations, it is only the unemployed for which high and medium skilled workers have a higher probability of a career change. Across industries, low skilled workers have a higher probability of changing career when mobility is through employment or inactivity, but not through unemployment.

Table 2 also shows the effects of different types of job characteristics on the probability of a career change. This probability increases if the worker obtains a part-time versus a full-time job and if the worker obtains a temporary versus a permanent job. ${ }^{20}$ Women have a higher probability of a career change than men. Furthermore, the larger the household someone is part of, the less likely a person is to change careers. That is, $\mathrm{Hm}$ is lower for persons who are married or cohabitate. It also decreases, although not significantly, in the number of children.

The Probit estimates also reaffirm the results found in Table 1 and Figures 3, 6, and 7. We find that for employed workers, career changes are more likely among those employed workers that made voluntary $E E$ transitions and among those that were actively searching for a job (our baseline category with respect to all the search channels). Unemployed workers are more likely to make career changes than employed (our baseline category) or inactive workers; while a career change through unemployment is more likely to occur at longer unemployment spells.

Using individual-level data in the Probit regression allows us to shine a more detailed light on search method workers employed to find their new jobs and how it affects their chance of changing careers. In particular, the explanatory variables listed in Rows 18 through 21 get at this. ${ }^{21}$ We find that those workers who find jobs responding to ads are more likely to change careers then those who find jobs through other means.

Conditioning on the worker-, job-, and search- characteristics does not erase the significance of the procyclicality of career changes. This suggests that the business cycle movements in occupational and industry mobility of workers is not the result of the composition of the group of workers with a previous career that gets hired changing with the cycle.

As can be seen from the marginal probability estimates reported in Row 1 and columns I and V of Table 2, a one percentage point increase in the unemployment rate reduces $H m$ by 0.6 percentage

\footnotetext{
${ }^{19}$ Details about the definitions of the explanatory variables are provided in the Appendix.

${ }^{20}$ The exception is that for unemployed workers obtaining a permanent job increases the probability of a career change.

${ }^{21}$ The baseline category "direct application to employers".
} 
points for occupations and 1.4 percentage points for industries. ${ }^{22}$ Contrary to the discussion above, these results are based on the whole sample period and not only on comparing the Great Recession and its aftermath with the preceding episodes in the data.

The higher sensitivity of occupation switches compared to industry switches to the aggregate unemployment rate is offset by the higher sensitivity of occupational mobility with respect to regional component of the unemployment rate, reported in Row 2 of Table 2. Taking the results of Rows 1 and 2 of Table 2 together both occupational as well as industry mobility comove very significantly with labour market conditions.

\subsection{Origins and Destinations}

We now turn to analyse the transition matrices of workers' career changes. These matrices provide useful information on the mobility patterns of workers as they shed light on the potential importance of individual occupations or industries in driving overall mobility. Table 3 shows the transition matrix for workers changing careers across occupations. ${ }^{23}$

This matrix shows that all occupations exhibit a high degree of mobility. The dark-shaded cells of the list the fraction of hires that get hired in the same major occupation as they were working in before. Looking at the numbers for all hires, labeled as "Total". the probability of a career change ranges from $61 \%$ for sales occupations to $32 \%$ for professional occupations.

Across occupations, however, we observe some clustering by skill level. To show this, we group together those occupations that require similar skill levels. This results in three groups of high-, medium, and low skilled occupations. Each of these groups consists of three major occupation codes. Career changes within each of these groups are highlighted in light grey as the block diagonal in the transition matrix. As can be seen, the transition probabilities in the grey cells tend to be higher than those in the other cells. There are two destination occupations that are notable exceptions to this pattern. First, a substantial number of career changes out of high-skill occupations result in jobs in "Clerical and administrative" jobs. Second, the miscellaneous ninth category absorbs a large number of career switchers from middle-skilled jobs. ${ }^{24}$

Moreover, workers are more likely to stay within their skill category or move to the highest skill category after an $E E$ transitions and more likely to move to a lower skill category through a $U E$ or $I E$ transition. ${ }^{25}$ These patterns suggest that workers tend to move more often to occupations that demand skills closer to the ones they can supply. However, conditional on moving to a different skill category, workers are more likely to make career changes that involve an upgrade in the skill level

\footnotetext{
${ }^{22}$ Because these are marginal probability estimates, this interpretation is for the "average" hire in terms of the covariates in our sample.

${ }^{23}$ To construct the transition matrix for occupations we have combined the two occupation classifications. We do this as our results hardly change when considering a separate transition matrix for each classification and the similarity in the labels across their occupational categories (see the Appendix for details) allows us to save space. Furthermore, we present the results for the entire period of study and not before and during the Great Recession, as the transitions matrices for the Great Recession period have the same characteristics as those for the pre-recession period. For the sake of brevity, we limit ourselves to the discussion of origins and destinations for occupations here.

${ }^{24}$ These patterns for occupational transitions are remarkably similar to those documented in Hobijn (2012) for the U.S.

${ }^{25}$ When making a career change outside a given skill category, workers in high skill occupations are more likely to move to an occupation in the medium skill category; workers in the medium skill category are more likely to move to an occupation in the low skill category. However, workers in the low skill category are more likely to move to an occupation in the medium skill category. The exception are those workers in the clerical/admin and secretarial occupations, who are more likely to move to an occupation in the high skill category conditional on a career change.
} 
through direct $E E$ transitions, while career changes that involve a lower skill level are more likely through spells of non-employment. This evidence reinforces our view that occupations mobility through $E E$ transitions are more likely to be voluntary career changes in which workers mostly pursue upward career moves, while occupational mobility through non-employment are more likely to be involuntary career changes.

\subsection{Wage gains}

The different nature of $E E$ hires, on the one hand, and $U E$ hires, on the other, is even more apparent when one looks at the different real wage gains they result in. ${ }^{26}$ Because we are interested in wage changes, our analysis only includes hires for which we have data in waves 1 and 5 of the survey, depicted in Figure 2. In particular, that means that for workers who flow through unemployment, we only have wage changes for those with an unemployment spell shorter than 4 quarters.

Long-run perspective Table 4 shows the probability that the hire of a worker with previous work experience results in a wage gain. The table lists this probability conditional on whether the hire involves a change in career and on the level of the wage earned in the previous job, measured in terms of the percentile of the wage distribution. The probability of a positive wage gain is much higher for workers who start off in a job with a low wage. For those workers, this probability is also higher when they change careers than when they did not. For workers make an above-median wage, however, the probability of obtaining a positive wage growth when changing employer is closer to $30 \%$ and is higher for those that do not change careers. This suggests that a large part of the voluntary career mobility through job-to-job moves that we document is workers moving up the job ladder to progress their careers.

Where Table 4 provides information about the sign of the wage change, the columns for the "Whole sample" in Table 5 show the distribution of the magnitude of wage changes. The first takeaway from this table is the large degree of dispersion in wage growth that results from a change in employers. Below the 50th percentile of each distribution, workers can experience large negative wage losses when moving employers, while above the 50th percentile workers experience large wage gains. ${ }^{27}$

The most striking feature of the distributions shown in Table 5 is that the dispersion of wage gains is larger for career movers than for career stayers. This also holds true when we condition on whether the worker changed employers through an intervening spell of unemployment or not. Relative to stayers those who changed careers have higher wage growth at and above the 50th percentile of the wage growth distribution; while the opposite happens below the 50th percentile. This evidence again supports our interpretation that workers typically change careers for wage

\footnotetext{
${ }^{26}$ Gross real weekly wages are obtained by deflation the gross weekly wage by the CPI. Given that the LFS only provides wage information on its 5 quarter sample and only for a worker's Q1 and Q5 interview wave, we are not able to subdivide the analysis by demographic or job characteristics or by the other stratifications we used in the previous sections without running into small sample problems. We also focus our attention to those workers that made $E E$ or $U E$ transitions given the small sample of those workers making $I E$ transitions for which we have wage information. Further information about Q1 and Q5 wages is only available as from 1996. See the Appendix for further details.

${ }^{27}$ These numbers are consistent with the large set of evidence that finds re-employment wage loses for displaced workers (see Jacobson, et al. 1993) and wage gains for workers that undergo direct $E E$ transitions (see Topel and Ward, 1992). The actual wage losses due to displacement are likely underestimated in our data since our sample only contains unemployment spells that lasted shorter than 4 quarters.
} 
gains bigger than for those that stayed in the same occupation. It might seem counterintuitive that, although career changes through unemployment are largely involuntary, they do tend to lead to positive wage gains that are larger than those obtained by unemployed workers who will stay in the same career. However, this evidence is not inconsistent with a theory in which these potentially larger wage gains can only be obtained after a costly reallocation process which only becomes worthwhile after job prospects in the original career have deteriorated sufficiently (see, for example, Carrillo-Tudela and Visschers, 2014).

Cyclical patterns The last six columns of Table 5 show how the distribution of wage changes varies over different business cycle episodes in the U.K. labour market. Across occupations and industries the wage growth distribution of those workers that change careers through unemployment shifts down during the recession. The decrease is stronger across occupations than industries. Further, the shift in the wage growth distribution of those who changed occupations through unemployment is sufficiently big that their wage gains are now below the wage gains of career stayers even at the 75th percentile of the wage growth distribution. In contrast, the wage growth distribution of workers that changed employers directly through an $E E$ transitions or those that changed employers through unemployment but did not undertake a career change, do not seem to respond as much to business cycle conditions. ${ }^{28}$

The evidence presented suggests that career changers have a higher probability of a substantially large wage increase than career stayers. However, during the recession the wage gains of occupational changers decrease to the point that, for unemployed workers, these have become smaller than the wage gains from changing employer in the same occupation. As argued, for example, in Carrillo-Tudela and Visschers (2014), the decrease in the gains of reallocation can help explain the drop in the probability of a career change during the recession, documented in subsection 3.2.

\section{Conclusion}

Thus, there are basically two types of career changes in our data. Those that are voluntary and generally go from job to job and those that are involuntary and tend to result in an episode of unemployment. In the U.K. labour market, the former type make up the bulk of career changes. This type of career switch involves workers pursuing better job opportunities that move them up the career ladder in terms of the skill levels of their jobs as well as in terms of compensation. Such career opportunities are more plentiful when the labour market is strong and the unemployment rate is low. As a consequence, they are procyclical in nature.

This procyclicality is partly offset by the second type of career moves. Involuntary career moves tend to increase when workers get laid off in recessions. With the increase in unemployment, the number of career switches of unemployed workers increases during recessions. However, this increase is relatively subdued, as the probability that an unemployed worker changes careers decreases in recessions, even though there are more long-term unemployed workers. This can be the result of, for example, employers getting more finicky about who they hire during downturns, and workers responding to lower expected gains from changing careers. Overall, a rise of this second type of

\footnotetext{
${ }^{28}$ These observations are also confirmed when regressing the wage growth of workers on output per worker and a time trend, showing that these patterns are not particular to the Great Recession.
} 
career moves is not enough to overturn the procyclicality of total career changes.

The bottom line is that, in terms of career switches, recessions are thus better described as "sullying" the reallocation of workers in the labour market than as "cleansing" the labour market from bad worker-job matches where the worker would have been better off in another career but have not pursued it due to frictions in the labour market. 


\section{References}

[1] Auray, Stephane, David Fuller, Damba Lkhagvasuren and Antoine Terracol. 2014. "A Dynamics Analysis of Sectoral Mobility, Worker Mismatch, and the Wage-Tenure Profile ". Mimeo, CREST-Ensai, France.

[2] Barlevy, Gadi. 2002. "The Sullying Effect of Recessions". Review of Economic Studies, 69 (1):65-96.

[3] Caballero, Ricardo and Mohamad Hammour. 1994. "The Cleansing Effect of Recessions". American Economic Review, 84 (5): 1350-1368.

[4] Carrillo-Tudela, Carlos, Bart Hobijn, and Ludo Visschers. 2014. "Career Changes Decline During Recessions ". FRBSF Economic Letters, No. 2014-09.

[5] Carrillo-Tudela, Carlos and Ludo Visschers. 2014. "Unemployment and Endogenous Reallocations Over the Business Cycle". CESifo Working Papers No. 4079.

[6] Daly, Mary C., Early Elias, Bart Hobijn, and Òscar Jordà. 2012. "Will the Jobless Rate Drop Take a Break?" FRBSF Economic Letter, 2012-37.

[7] Davis, Steven J. 1987. "Fluctuations in the Pace of Labor Reallocation." Carnegie-Rochester Conference Series on Public Policy, 27: 335-402.

[8] Davis, Steven J., and John Haltiwanger. 1992. "Gross Job Creation, Gross Job Destruction, and Employment Reallocation". Quarterly Journal of Economics, 107(3): 819-863.

[9] Economic Cycle Research Institute. 2014. "International Business Cycle Dates". https://www.businesscycle.com/ecri-business-cycles/ international-business-cycle-dates-chronologies [last accessed: 13/08/2014].

[10] Elsby, Michael W. L., and Jennifer Smith. 2010. "The Great Recession in the UK Labour Market: A Transatlantic Perspective." National Institute Economic Review, 214(October): R1R12.

[11] Faberman, Jason and Marianna Kudlyak. 2012. "The Intensity of Job Search and Search Duration". Mimeo, Federal Reserve Bank of Richmond, USA.

[12] Fujita, Shigeru and Guiseppe Moscarini. 2012. "Recall and Unemployment". Mimeo. Department of Economics, Yale University, USA.

[13] Pedro, Gomes. 2012. "Labour market flows: Facts from the United Kingdom". Labour Economics, 19(2): 165-175.

[14] Groshen, Erica L., and Simon Potter. 2003. "Has Structural Change Contributed to a Jobless Recovery?" Current Issues in Economics and Finance, 9(8): August 2003.

[15] Hodrick, Robert and Edward C. Prescott. 1997. "Postwar U.S. Business Cycles: An Empirical Investigation." Journal of Money, Credit, and Banking, 29(1): 1-16. 
[16] Hobijn, Bart. 2012. "The Industry-Occupation Mix of U.S. Job Openings and Hires." FRB SF Working Paper 2012-09.

[17] Hobijn, Bart, and Ayşegül Şahin. 2013. "Beveridge Curve Shifts Across Countries Since the Great Recession." IMF Economic Review, 61(4): 566-600.

[18] Jacobson, Louis, Robert LaLonde and Daniel Sullivan. 1993. "Earnings Losses of Displaced Workers. "American Economic Review, 83(4): 685-709.

[19] Jaimovich, Nir, and Henry E. Siu. 2014. "The Trend is the Cycle: Job Polarization and Jobless Recoveries. "Mimeo, Duke University.

[20] Jolivet, Gregory, Fabien Postel-Vinay and Jean-Marc Robin. 2006. "The Empirical Content of the Job Search Model: Labor Mobility and Wage Distributions in Europe and the US." European Economic Review, 50: 877-907.

[21] Jovanovic, Boyan and Robert Moffitt. 1990. "An Estimate of a Sectoral Model of Labor Mobility". Journal of Political Economy, 98 (4): 827-852.

[22] Kambourov, Gueorgui and Iourii Manovskii. 2009. "Occupational Specificity of Human Capital". International Economic Review, 50 (1): 63-115.

[23] Kambourov, Gueorgui and Iourii Manovskii. 2008. "Rising Occupational and Industry Mobility in the United States: 1968-97". International Economic Review, 49 (1): 41-79.

[24] Lazear, Edward P., and James R. Spletzer. 2012. "Hiring, Churn, and the Business Cycle." American Economic Review, 102(3): 575-79.

[25] Lilien, David M. 1982. "Sectoral Shifts and Cyclical Unemployment.". Journal of Political Economy, 90 (4): 777-793.

[26] Longhi, Simonetta and Mark Taylor. 2011. "Occupational Change and Mobility Among Employed and Unemployed Job Seekers". Institute for Social and Economic Research, University of Essex, WP No. 2011-25.

[27] Lynn, Peter, and Emmanuela Sala. 2006. "Measuring Change in Employment Characteristics: The Effects of Dependent Interviewing". International Journal of Public Opinion Research, 18(4): 500-509.

[28] Mellow, Wesley, and Hal Sider. 1983. "Accuracy of Response in Labor Market Surveys: Evidence and Implications". Journal of Labor Economics, 1(4): 331-344.

[29] Mortensen, Dale and Christopher Pissarides. 1994. "Job Creation and Job Destruction in the Theory of Unemployment". Review of Economic Studies, 61(3): 397-415.

[30] Moscarini, Guiseppe and Francis Vella. 2008. "Occupational Mobility and the Business Cycle". Mimeo, Yale University, USA.

[31] Moscarini, Guiseppe and Kaj Thomsson. 2007. "Occupational and Job Mobility in the US". Scandinavian Journal of Economics, 109 (4): 807-836. 
[32] Murphy, Kevin and Robert Topel. 1987. "The Evolution of Unemployment in the United States: 1968 - 1985". NBER Macroeconomics Annual 1987, 2: 11-68.

[33] Office for National Statistics. 2011a. Labour Force Survey User Guide, version 1.0, ONS.

[34] Office for National Statistics. 2011b. User Guide LFS: Two-Quarter and Five-Quarter Longitudinal Datasets, version 1.0, ONS.

[35] Patterson, Christina, Ayşegül Şahin, Giorgio Topa, and Giovanni L. Violante. 2013. "Mismatch Unemployment in the U.K." mimeo, Federal Reserve Bank of New York.

[36] Ravenna, Federico, and Carl Walsh. 2012. "Labor Market Flows with Skill Heterogeneity in a Monetary Policy Model." Journal of Money, Credit and Banking, 44(s2): 31-71.

[37] Sedláček, Petr. 2014. "Match Efficiency and Firms' Hiring Standards. "Journal of Monetary Economics, 62:123-133.

[38] Smith, Jennifer C. 2012. "Unemployment and Mismatch in the U.K." Mimeo, University of Warwick.

[39] Topel, Robert and Michael P. Ward. 1992. "Job Mobility and the Careers of Young Men," in Quarterly Journal of Economics, 107(2): 439-479.

[40] Xiong, Hui. 2008. "The U.S. Occupational Mobility from 1988 to 2003: Evidence from SIPP". Mimeo, University of Toronto, Canada. 


\section{Appendix}

\section{A Data details}

In this appendix we describe the main aspects of the U.K. Quarterly Labour Force Survey. We limit ourselves to those points that are relevant for understanding how we constructed the results in the main text. More information about the U.K. Quarterly Labour Force Survey can be found in Office for National Statistics (2011a, 2011b).

Occupation and Industrial Classifications The U.K. LFS uses the Standard Occupational Classification (SOC) to code occupations. The occupational coding system was revised in 2001 changing from the SOC 1990 to the SOC 2000. The latter lasted until 2010Q4. A drawback of this revision is that the SOC 1990 and SOC 2000 are not compatible. ${ }^{29}$ Our focus on mobility across 1-digit or major occupational groups helps to reduce the potential incompatibility errors. Indeed, at this level of aggregation, the agreement between the two SOC is of 73.5 percent. The disagreement between the two classifications, however, introduces a level in some of the occupational series. To correct for shift, we adjust all 5-quarter centred moving average series, by running an OLS regression on the log of the corresponding series with respect to a linear time trend, the log of output per worker and a dummy for the structural break, which takes value of zero before 2000Q4 and one after. We then used the coefficient estimate of the dummy variable (irrespectively if it was significant or not), $\beta$ to adjust the series up to $2000 \mathrm{Q} 4$ by multiplying the series by $e^{\beta}$ during this period.

At a 1-digit level, the SOC 1990 and SOC 2000 imply 9 occupational groups. The occupations in the SOC 1990 are: (1) Managers and administrators, (2) Professional occupations, (3) Associate professional and technical occupations, (4) Clerical and secretarial occupations, (5) Craft and related occupations, (6) Personal and protective service occupations, (7) Sales occupations, (8) Plant and machine operatives, (9) Other occupations. The occupations in the SOC 2000 are: (1) Managers and senior officials, (2) Professional occupations, (3) Associate professional and technical occupations, (4) Administrative and secretarial occupations, (5) Skilled trades occupations, (6) Personal service occupations, (7) Sales and customer service occupations, (8) Process, plant and machine operatives, (9) Elementary occupations.

To code industries, the U.K. LFS uses the Standard Industrial Classification (SIC). In this case the U.K. LFS does provide homogenised industry information for workers for the entire sample period based on the SIC $1992 .{ }^{30}$ We focused our analysis on industrial mobility based on sections which roughly corresponds to a level of aggregation of 1-digit. This implies 15 industry categories: (1) Agriculture, hunting and forestry, (2) Fishing, (3) Mining and quarrying, (4) Manufacturing, (5) Electricity, gas and water supply, (6) Construction, (7) Wholesale and retail trade including repairs, (8) Hotels and restaurants, (9) Transport, storage and distribution, (10) Financial intermediation, (11) Real estate, renting and business activities, (12) Public administration and defence, social security, (13) Education, (14) Health and social work, (15) Other community, social and personal service activities, (16) Private households with employed persons, (17) Extra-territorial

\footnotetext{
${ }^{29}$ Additionally, there is no occupational information provided for 2001Q1.

${ }^{30}$ The classification changes in 2009 to the SIC 2007.
} 
organisations and bodies (e.g. UN, EC, OPEC, etc.).

Analysis of Workers' Flows In the text we have conditioned workers' flows by whether workers declared they changed employers voluntarily or not, were actively searching for a job, wanted a job or not and by the duration of the completed unemployment spell. We now describe how we constructed each of these categories.

In the U.K. LFS employed workers are asked the reason why they left their previous employer. Using these reasons we construct three groups. The voluntary group consists of those employed workers who changed jobs because they "resigned", went to "education or training" and "gave up for family or personal reasons". The involuntary group consists of those employed workers who left their last job because they were "dismissed", "made redundant/took voluntary redundancy", "temporary job finished" and "gave up work for health reasons". The other group consists of those employed worker who left their last job because they "took early retirement, "retired and due to "other reasons. Overall, voluntary employer changes account for $48 \%$ of total $E E$ transitions, while involuntary employer changes account for $24 \%$ and the remainder by the 'other' category. From those employed workers that experienced a voluntary or involuntary separation, over $85 \%$ found another job without an intervening spell of non-employment.

Employed workers are also asked whether they were actively searching for a job and which search channels did they use. We categorise workers using a "job centre" when they declared that their main method of search was "visit a job centre, job market or jobs and benefit centres", "visit a job club", "have your name on the books of a private employment agency", or "visit a careers office. Workers in the category "ads" were those that declared that their main method of search was "advertise for jobs in newspapers and journals", "answer advertisements in newspapers and journals", "study situations vacant in newspapers or journals". Workers in the category "direct applications" were those whose main method was "apply directly to employers". Workers in the category "ask a friend or relative" correspond to those that declared their main method of search to be "ask friends, relatives, colleagues or trade unions about jobs". The last category "do anything else includes those who responded "wait for the results of an application for a job", "look for premises or equipment", "seek any kind of permit", "try to get a loan or other financial backing for a job or business", and "do anything else to find work". Among the employed, $77 \%$ of workers that made an $E E$ transitions declared they were not actively searching for a job and the reminder $33 \%$ did.

Workers who declared themselves as non-participants in the labour market were considered to "want a job" if they were seeking but unavailable because they were a student, looking after family, temporarily sick or injured, long-term sick or disabled or due to other reasons or no reasons given. In addition we categorise as wanting a job those non-participants that are not seeking, but would like to work and are waiting for results of job applications, believe no jobs are available, have not looked, are a student, looking after family, temporarily sick or injured, long-term sick or disabled, or no reason given. Those who "do not want a job" are those workers that declared they are not seeking, would not want to work and are waiting for results of job applications, do not need or want a job, are a student, looking after family, temporarily sick or injured, long-term sick or disabled, retired or or due to other reasons or no reasons given. Although there are many reasons why a worker declares him or herself out of the labour force, for those that want or do not want a job, 
there are three main reasons: being either a student, looking after family or long-term sick. In particular, $75 \%$ of workers who wanted a job are in these three categories, while $82 \%$ of those that did not want a job are in these categories. Among the inactive, those that want a job represent on average $30 \%$ of the non-participants, and those that do not want a job the remainder $70 \%$.

Finally, to construct the category of unemployed workers that found a job within the first 2 quarters of their unemployment spell and the category of those that found a job after that, we use the following categorical variable for the duration of unemployment: (1) Less than 3 months, (2) 3 months but less that 6 months, (3) 6 months but less than 12 months, (4) 1 year but less than 2 years, (5) 2 years but less than 3 years, (6) 3 years but less than 4 years, (7) 4 years but less than 5 years, (8) 5 years or more. We label workers in (1) and (2) as "less than or equal to 2 quarters" and the rest as "more than 2 quarters".

Probit Analysis To further analyse the workers' likelihood of a career change, we use the latent variable model

$$
P_{i j}=\mathbf{x}_{i}^{\prime} \beta_{\mathbf{j}}+\varepsilon_{i j}
$$

where $P_{i j}$ is the latent variable that measures the probability of an occupational or industry change, $\varepsilon_{i j}$ is i.i.d and follows a multivariate normal distribution, $i$ represent individuals and $j$ outcomes. For all those workers that changed employers (through employment or non-employment), the dependent variable takes the value of zero if the worker did not change occupation or industry and one if the worker did.

The vector $\mathbf{x}_{i}$ describes the explanatory variables. It includes variables which capture the effects of aggregate and local economic conditions through the aggregate unemployment rate, and the deviations of the regional unemployment rates from the aggregate unemployment rate in each quarter. The effects of workers' human capital through a quadratic on age, different skill categories and the duration of the job or unemployment spell. The skill categories are dummy variables that take the value of one if the worker has the corresponding skill level and zero otherwise. The high skilled category groups all those workers that have post school degrees, ranging from teaching qualifications to graduate studies. The medium skilled category groups all workers that achieved between a O-level or GCSE qualification to an A-level or equivalent qualification. The low skilled category groups all individuals with an educational attainment below O-levels or GCSE. For unemployed workers, the spell duration indicates the duration of unemployment and includes the eight categories mentioned above. For employed workers, this variable denotes the duration of employment with current employer in months. We also include a set of variables that measure further demographics such as a dummy for marital status, ${ }^{31}$ the number of children, and a dummy for gender. We also consider dummies for full-time jobs and whether the job was temporary or permanent. We include dummies for employment status and whether the change of employer was

\footnotetext{
${ }^{31}$ The classification of marital status before 2006Q2 has five options: (1) Single, never married, (2) Married, living with husband/wife, (3) Married, separated from husband/wife, (4) Divorced, and (5) Widowed. We set the value of this variable is one if the respondents marital status is (2), otherwise the value of this variable is zero. The classification of marital status after 2006Q2 has nine options. The first five options are identical to the previous classification. The additional options are (6) A civil partner in a legally-recognised Civil Partnership, (7) In a legally-recognised Civil Partnership and separated from his/her civil partner, (8) Formerly a civil partner, the Civil Partnership now legally dissolved, and (9) A surviving civil partner: his/her partner having since died. Under the classification of marital status after 2006Q2, we set the value of mar/cohab to one if a respondent whose marital status is (2) or (6), and zero otherwise.
} 
for involuntary or for other reasons, where we take voluntary reasons as our baseline category. Finally, we include dummies for the methods of job search and whether non-participants declared they wanted a job or not. All dummies take the value of one if the respective worker-, job-, and search- characteristic is equal to the label of the dummy. Otherwise, the dummy takes the value of zero.

Wage Analysis To analyse the distribution of wage growth we used the 5-quarter sample of the U.K LFS. When conditioning the analysis on employer changes through employment, unemployment or inactivity we only consider uninterrupted spells. That is, for $E E$ transitions, we only consider workers with employment histories (within the 5-quarters) of $E_{1} E_{2} E_{2} E_{2} E_{2}, E_{1} E_{1} E_{2} E_{2} E_{2}$, $E_{1} E_{1} E_{1} E_{2} E_{2}$, or $E_{1} E_{1} E_{1} E_{1} E_{2}$, where $E_{1}$ denotes the first employer and $E_{2}$ the second employer. For $E U E$ transition, we only consider workers with employment histories of $E_{1} U E_{2} E_{2} E_{2}$, $E_{1} E_{1} U E_{2} E_{2}, E_{1} E_{1} E_{1} U E_{2}, E_{1} U U E_{2} E_{2}, E_{1} U U U E_{2}$, or $E_{1} E_{1} U U E_{2}$. For $E I E$ transitions we consider employment histories with the same structure as for $E U E$ transitions. Finally, when analysing the wage growth for all workers we consider only those EE, EUE and EIE transitions. 
Table 1: Probability of career change, HSm.

\begin{tabular}{clcc}
\hline & & Occupation & Industry \\
\hline 1. & All workers & 0.49 & 0.53 \\
2. & Employed Workers, $E E$ & 0.47 & 0.52 \\
3. & Voluntary mobility & 0.48 & 0.52 \\
4. & Involuntary mobility & 0.44 & 0.51 \\
5. & Active search & 0.53 & 0.59 \\
6. & Non active search & 0.46 & 0.49 \\
7. & Unemployed Workers, $U E$ & 0.51 & 0.56 \\
8. & Unemp duration $<2 Q$ & 0.50 & 0.54 \\
9. & Unemp duration $\geq 2 Q$ & 0.56 & 0.61 \\
10. & Inactive Workers, IE & 0.49 & 0.50 \\
11. & Want a job & 0.50 & 0.52 \\
12. & Don't want a job & 0.47 & 0.48
\end{tabular}

Note: Shares reported are averages over all quarters in 1993Q12012Q3 sample for which data are available.

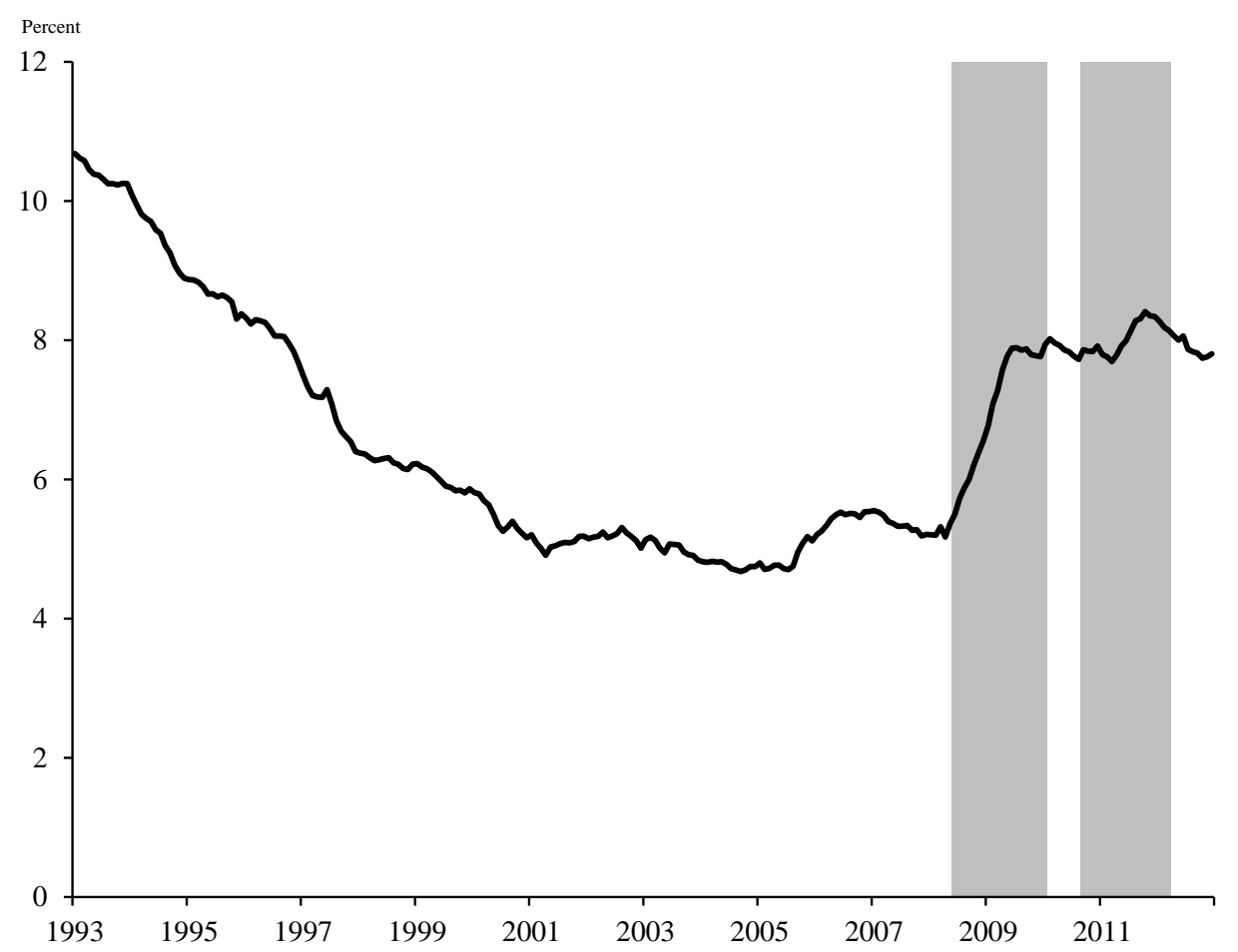

Source: U.K. LFS. Recessionshading are U.K. recession dates from ECRI. Monthly data, seasonally adjusted, 3-month centered moving average.

Figure 1: Unemployment rate in the United Kingdom. 


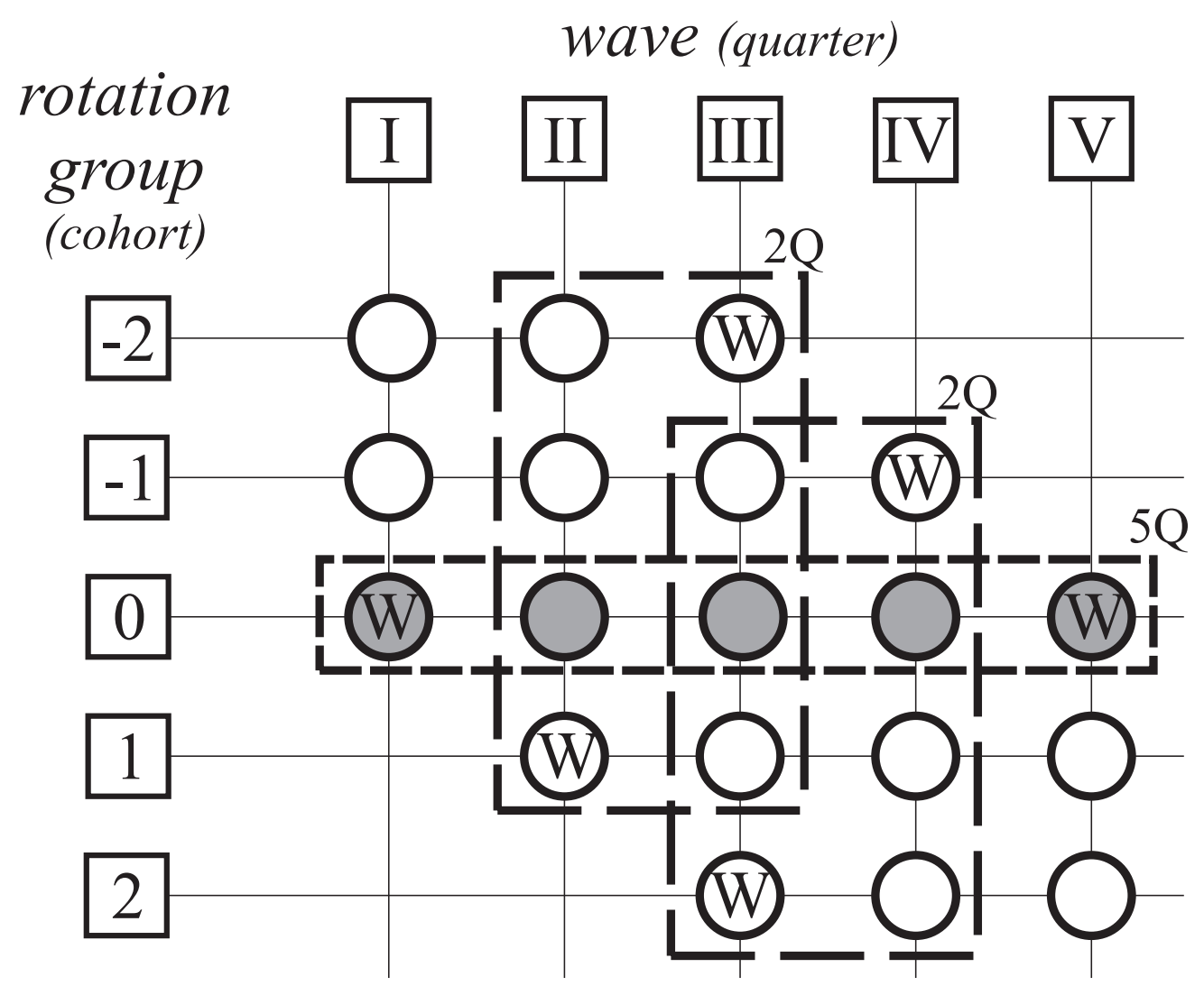

Figure 2: Rotating panel structure of U.K. Quarterly Labour Force Survey. 


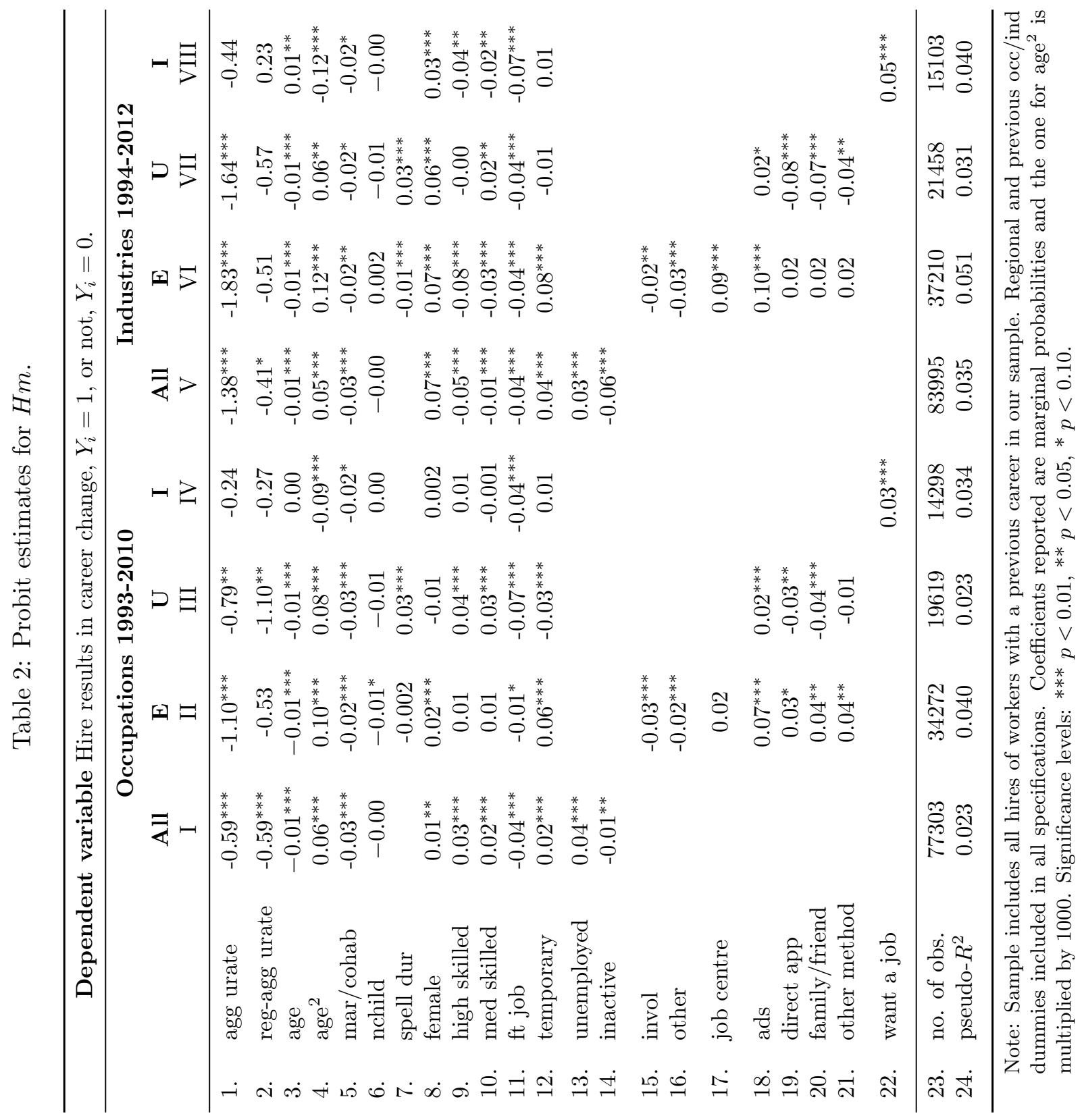




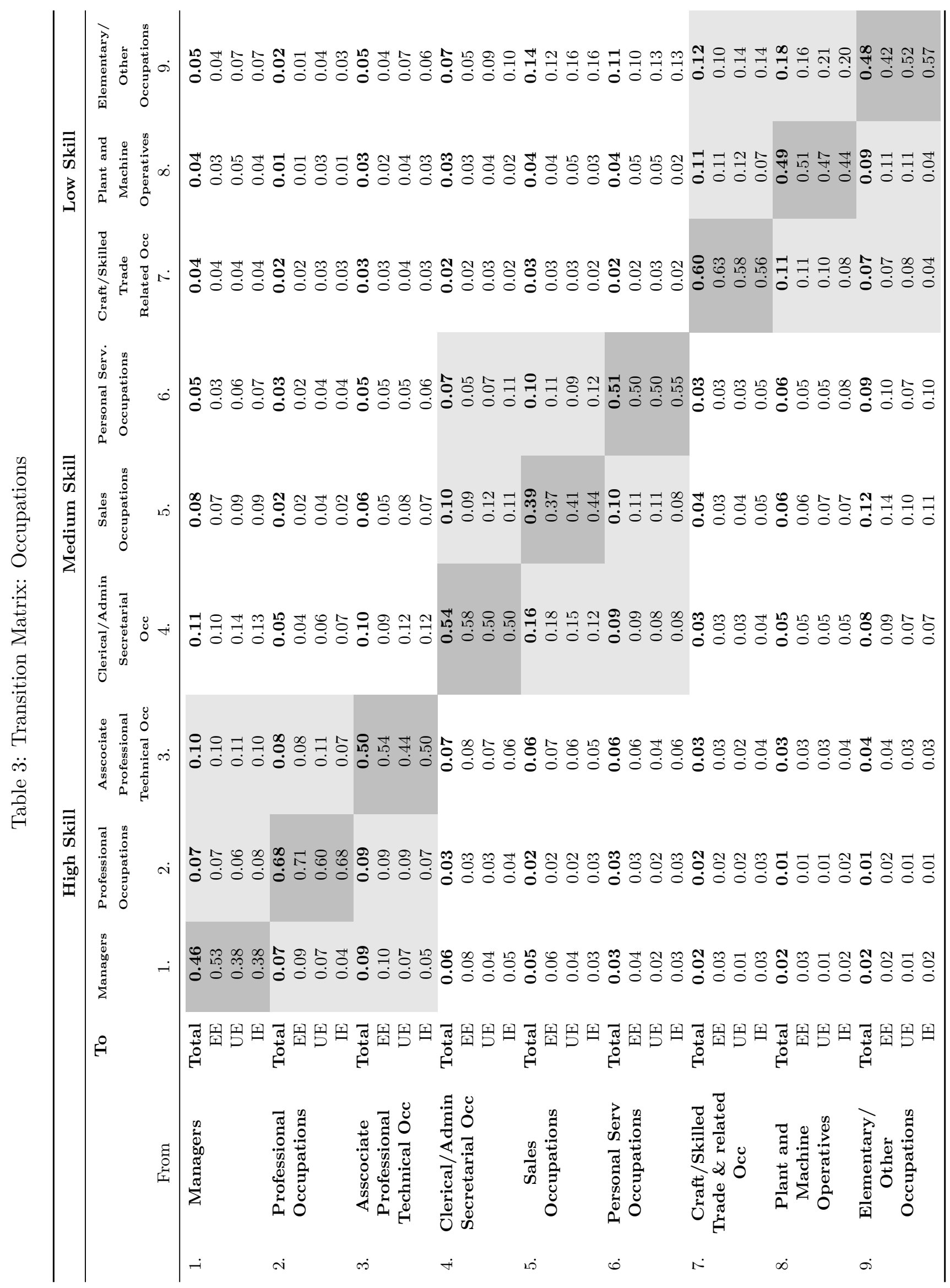


Table 4: Probability of positive real wage growth by percentile of wage in previous job

\begin{tabular}{|c|c|c|c|c|c|c|}
\hline & Quartile of the & & Occu & ations & Indi & tries \\
\hline & wage before & & Movers & Stayers & Movers & Stayers \\
\hline & changing jobs & & I & II & III & IV \\
\hline 1. & $0^{\text {th }}-25^{\text {th }}$ & Total & 78.5 & 67.0 & 79.9 & 65.5 \\
\hline & & $E E$ & 80.3 & 71.8 & 81.1 & 69.7 \\
\hline & & $E U E$ & 80.7 & 69.2 & 78.8 & 67.6 \\
\hline 2. & $25^{\text {th }}-50^{\text {th }}$ & Total & 56.9 & 51.1 & 57.5 & 51.1 \\
\hline & & $E E$ & 56.7 & 48.7 & 57.9 & 49.4 \\
\hline & & $E U E$ & 55.1 & 55.3 & 62.3 & 50.9 \\
\hline 3. & $50^{\text {th }}-75^{\text {th }}$ & Total & 37.6 & 46.1 & 36.1 & 46.3 \\
\hline & & $E E$ & 35.8 & 44.3 & 34.7 & 44.5 \\
\hline & & $E U E$ & 40.1 & 40.8 & 34.5 & 47.0 \\
\hline 4. & $75^{\text {th }}-100^{\text {th }}$ & Total & 27.0 & 35.8 & 26.4 & 37.2 \\
\hline & & $E E$ & 27.2 & 35.2 & 26.4 & 36.5 \\
\hline & & $E U E$ & 23.6 & 34.3 & 23.4 & 34.5 \\
\hline
\end{tabular}

Note: Percent of workers that receive a wage increase after changing jobs for all job changes in the sample. 


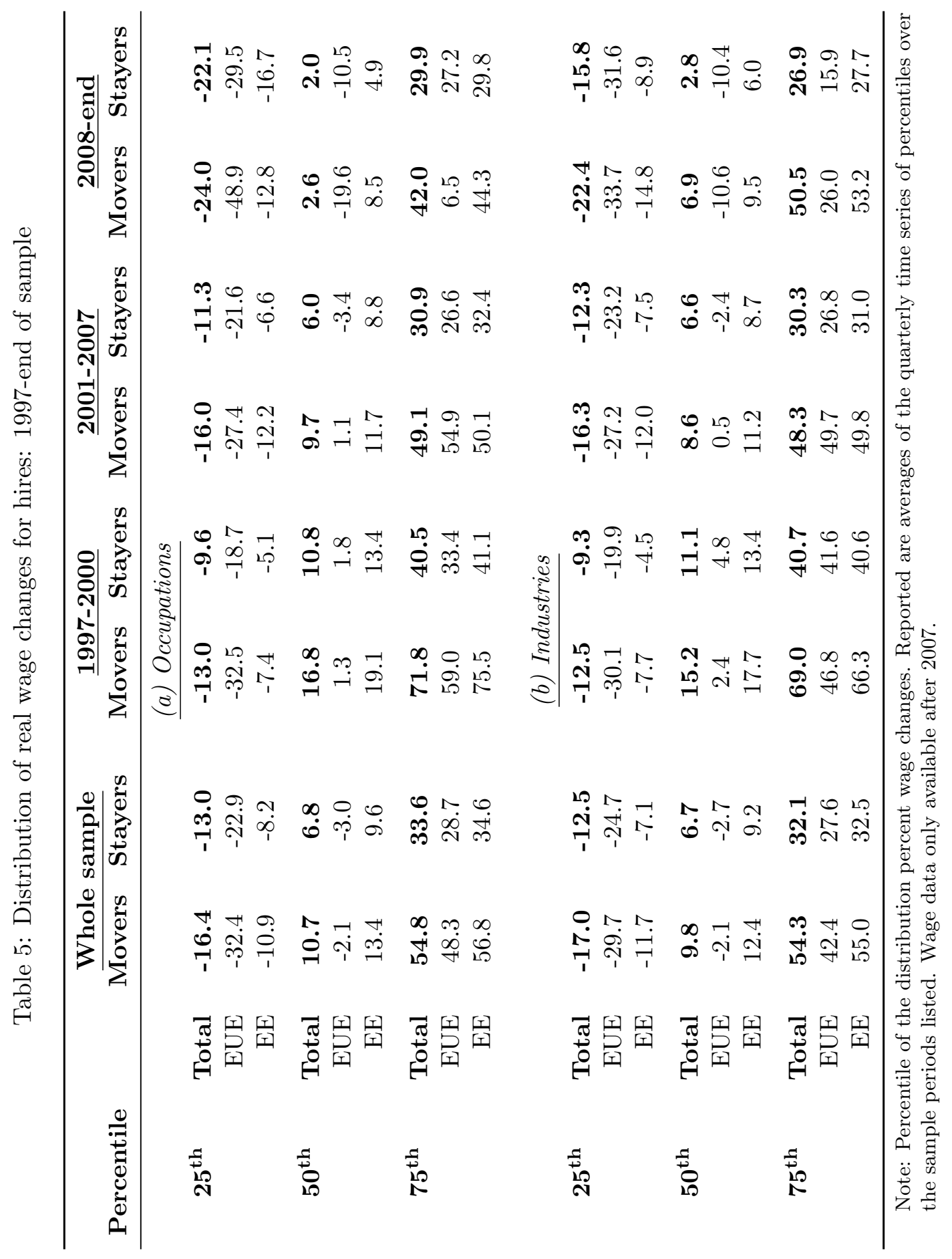




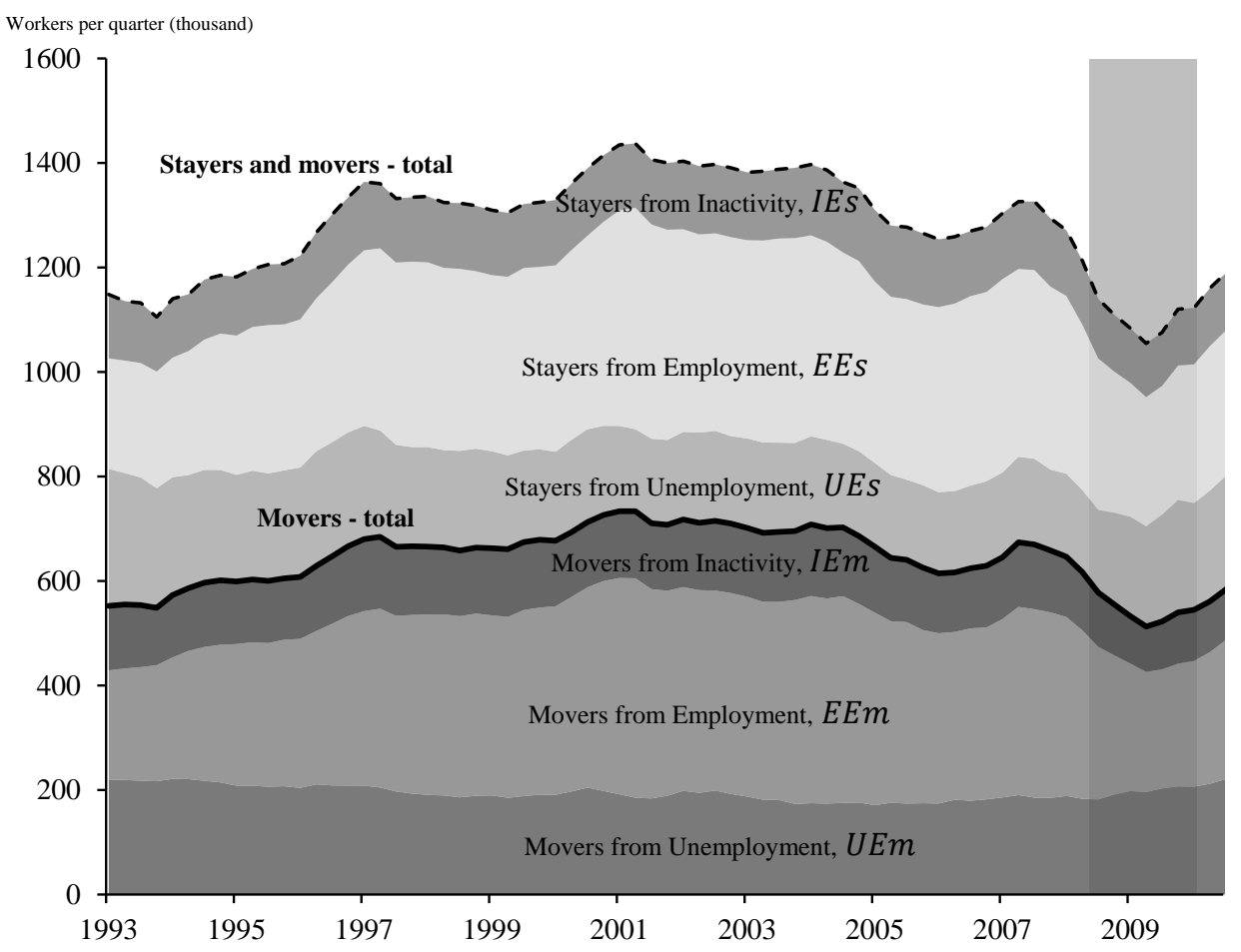

(a) Occupations

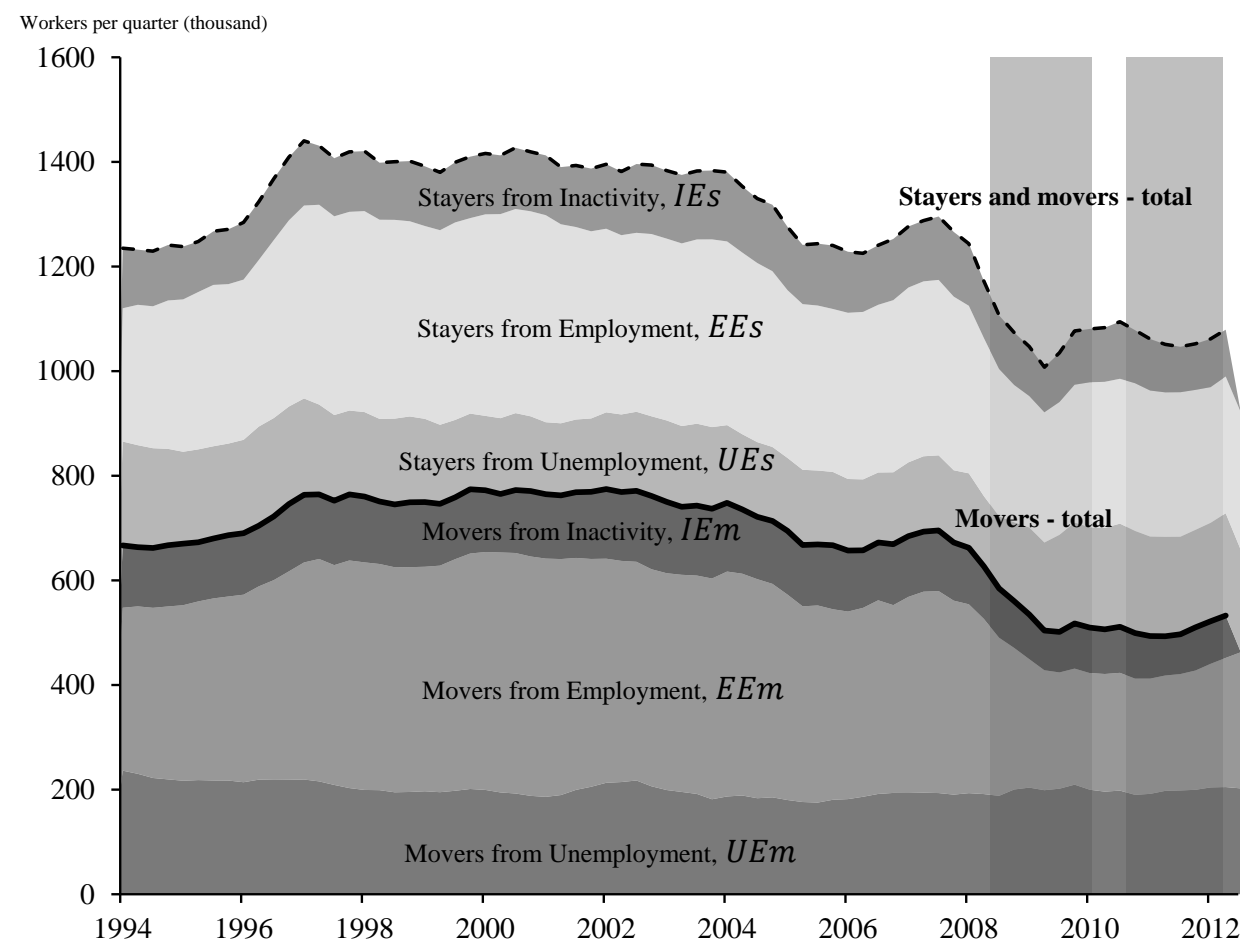

(b) Industries

Source: U.K. LFS and authors calculations. Recessionshading are U.K. recession dates from ECRI. Quarterly series, centered 5-quarter moving averages.

Figure 3: Hires of workers with ongoing careers, by career movers and stayers. 


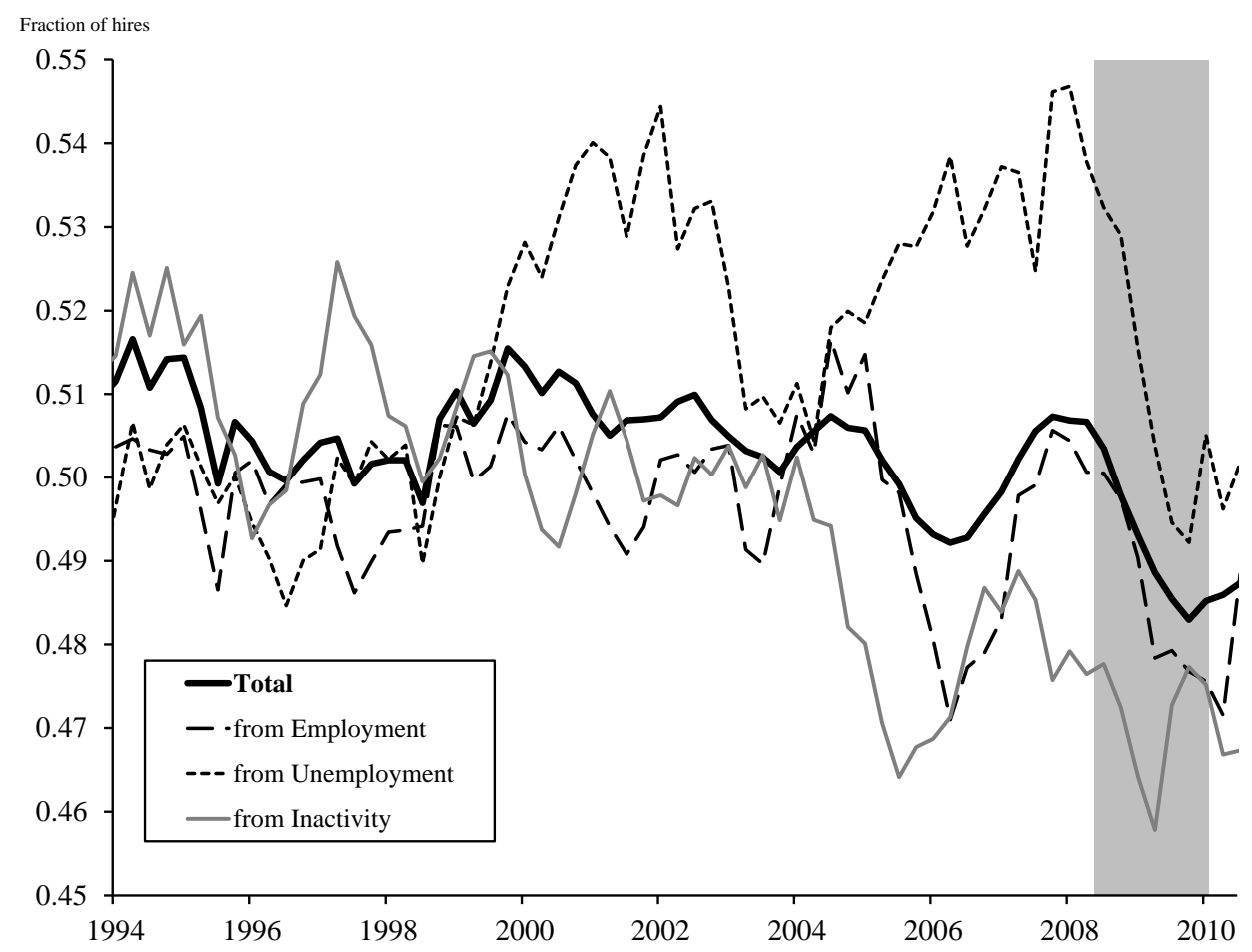

(a) Occupations

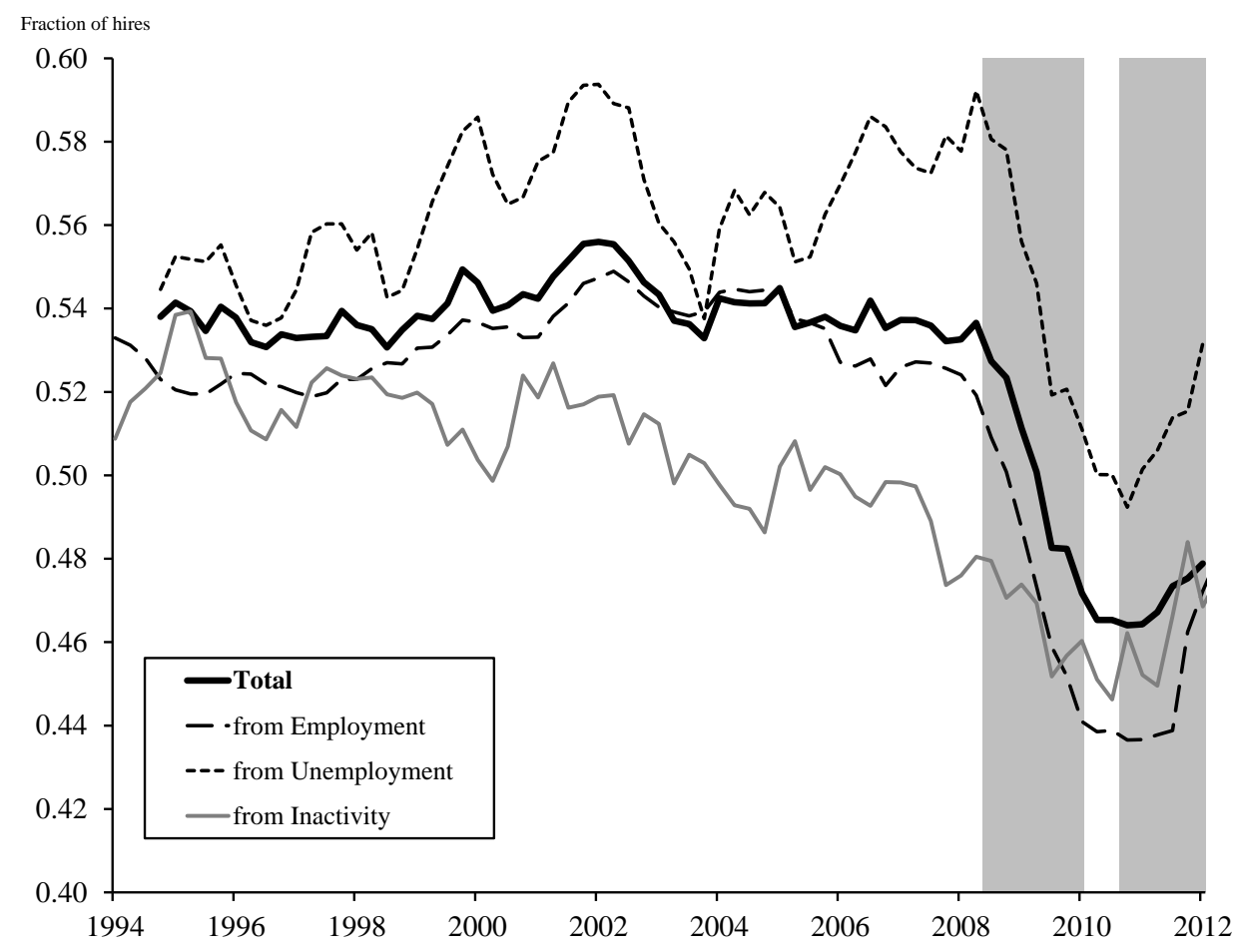

(b) Industries

Source: U.K. LFS and authors calculations. Recessionshading are U.K. recession dates from ECRI. Quarterly series, centered 5-quarter moving averages.

Figure 4: Probability of career change: $H m$, and $H S m$ for $S \in\{U, E, I\}$. 


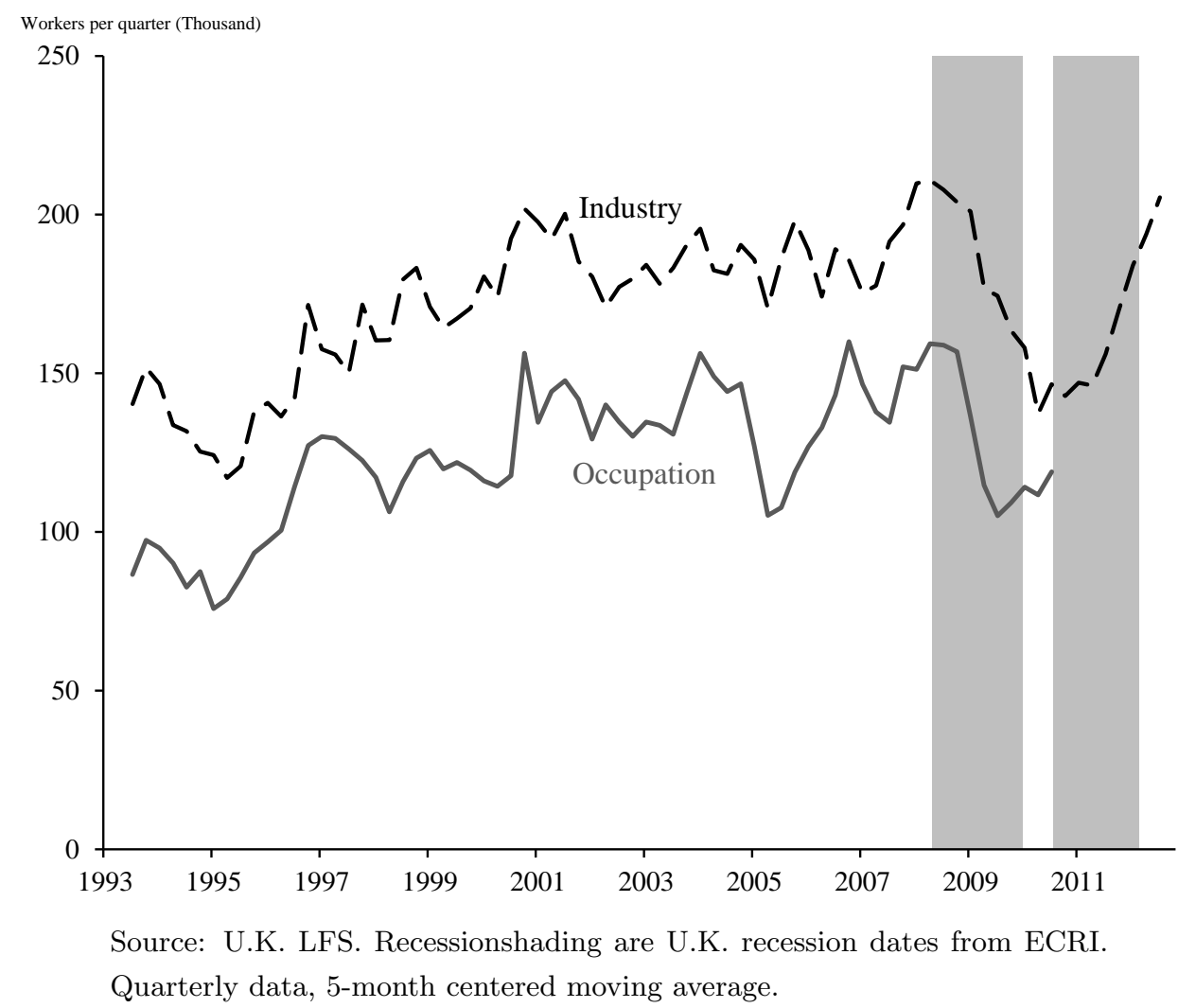

Figure 5: Net mobility, $N M_{t}$, for career changes to different occupations and industries. 

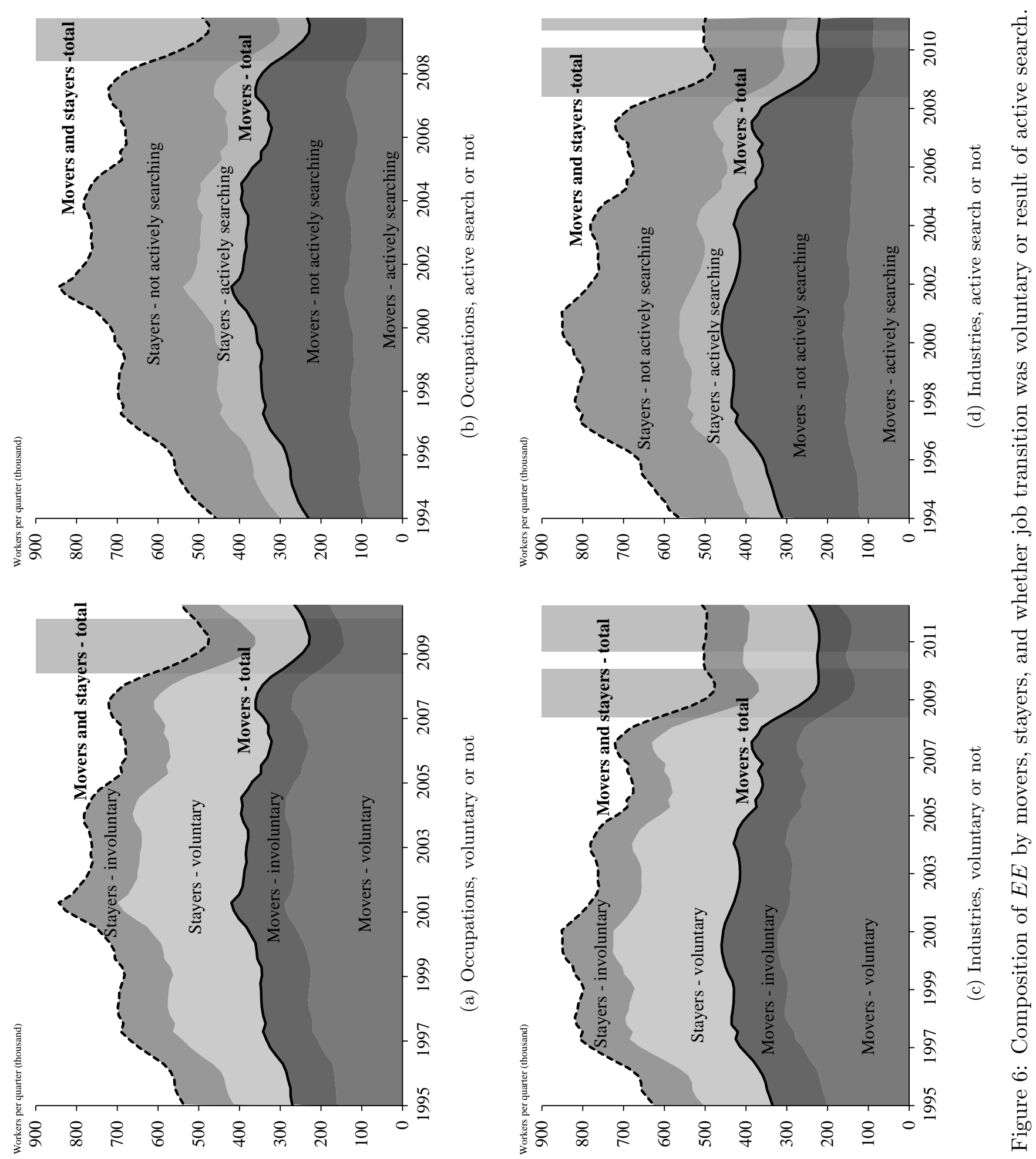


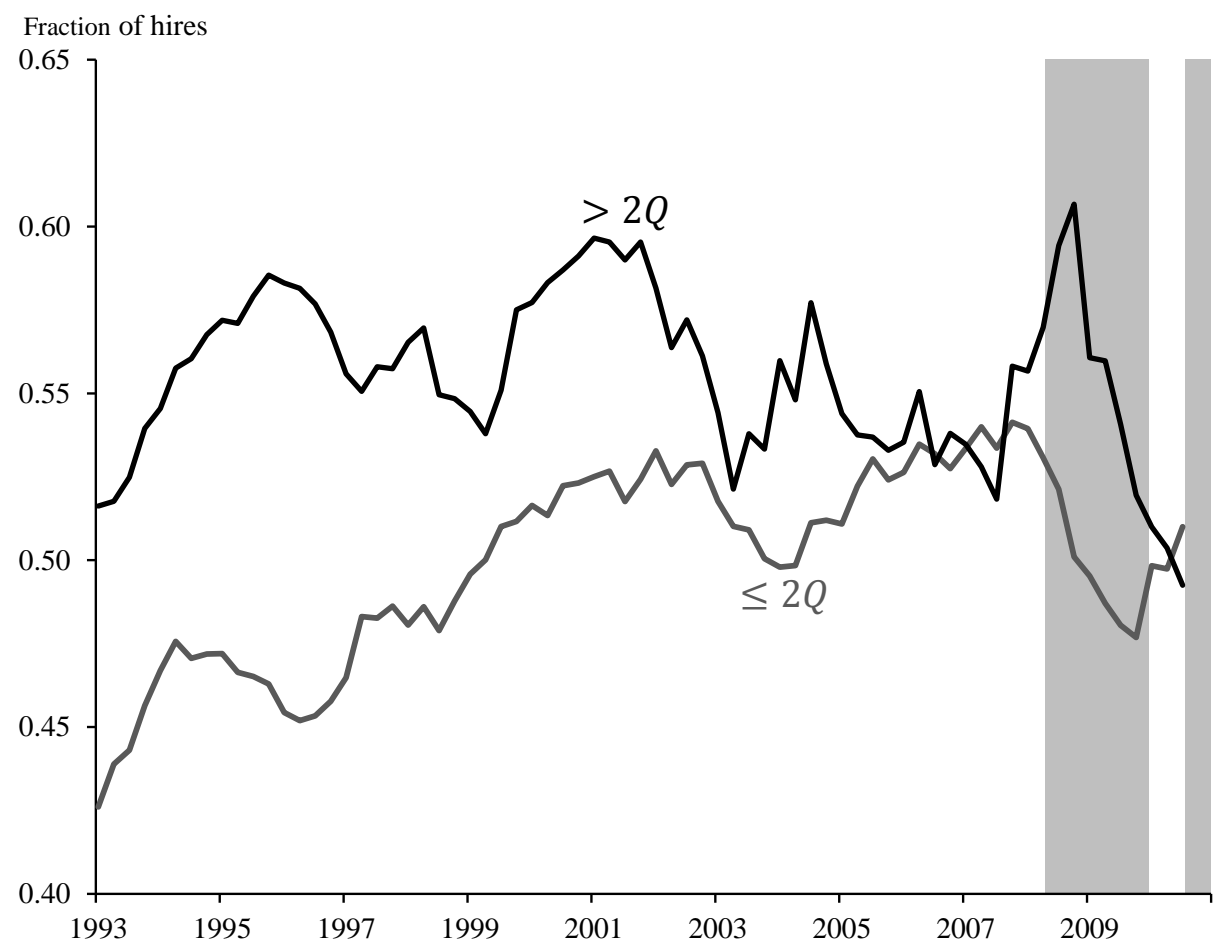

(a) Occupations

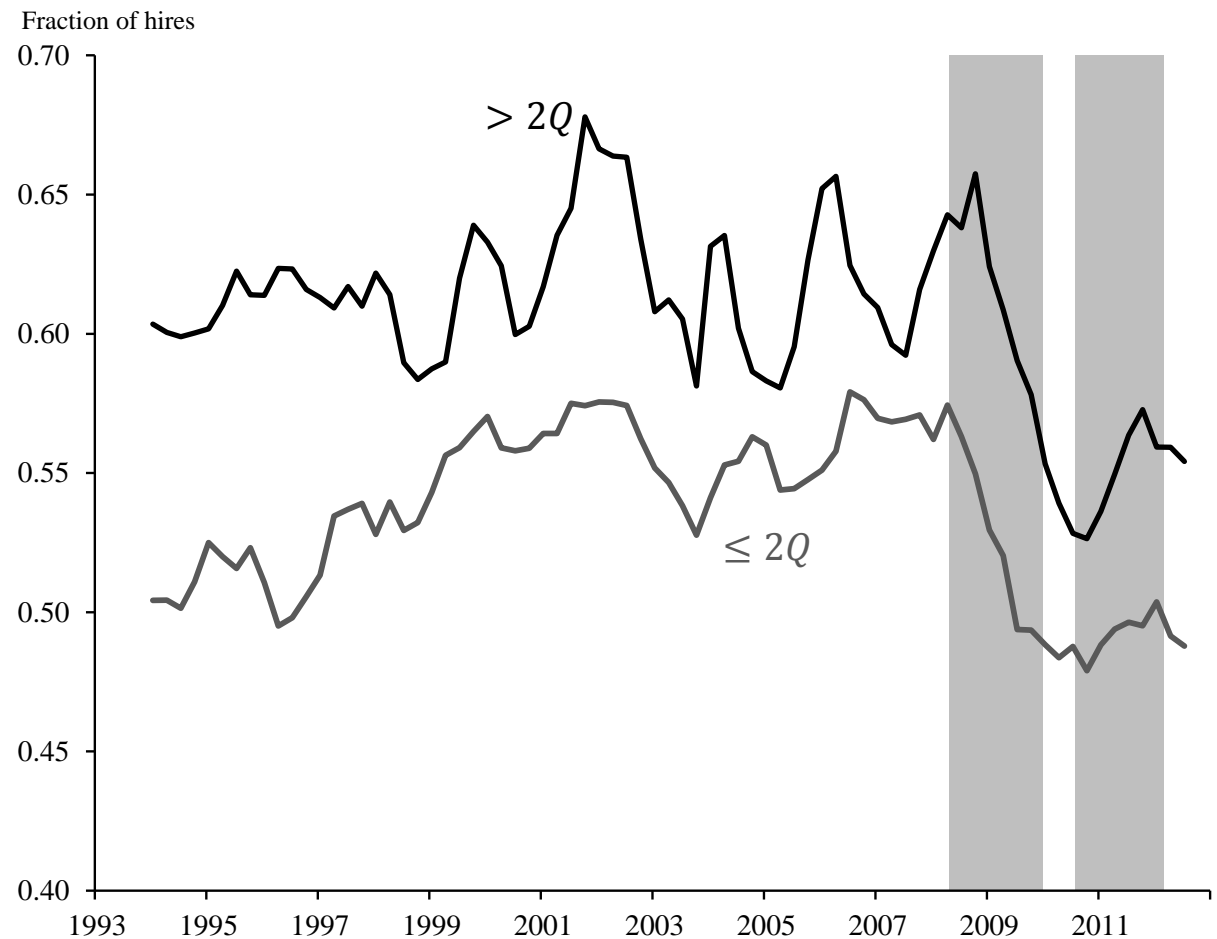

(b) Industries

Source: U.K. LFS and authors calculations. Recessionshading are U.K. recession dates from ECRI. Quarterly series, centered 5-quarter moving averages.

Figure 7: $H U m$ for workers finding jobs after spells shorter and longer than 2 quarters. 